\title{
Groundwater-surface water interactions
}

\author{
Marianne Stuart
}

\section{Better Thames}




\section{Outline}

- Groundwater bodies

- Baseflow

- Nitrate time bomb

- Hyporheic zone

- Boxford Observatory

- Floodplains

- Oxford Port Meadow Observatory

- Water quality

- Flooding

- Climate change 


\section{Groundwater bodies - overall chemical status}

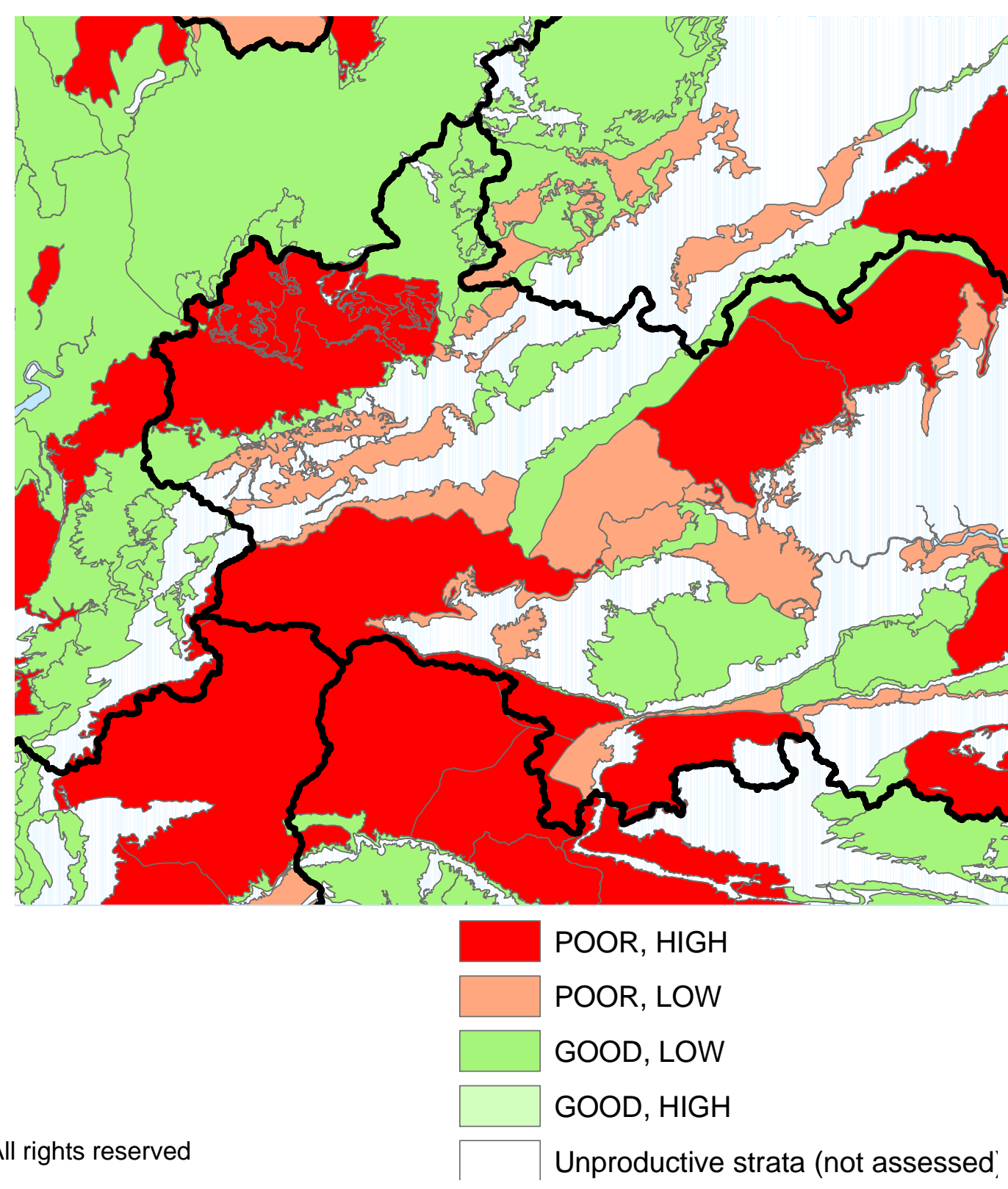




\section{Groundwater bodies - trends}

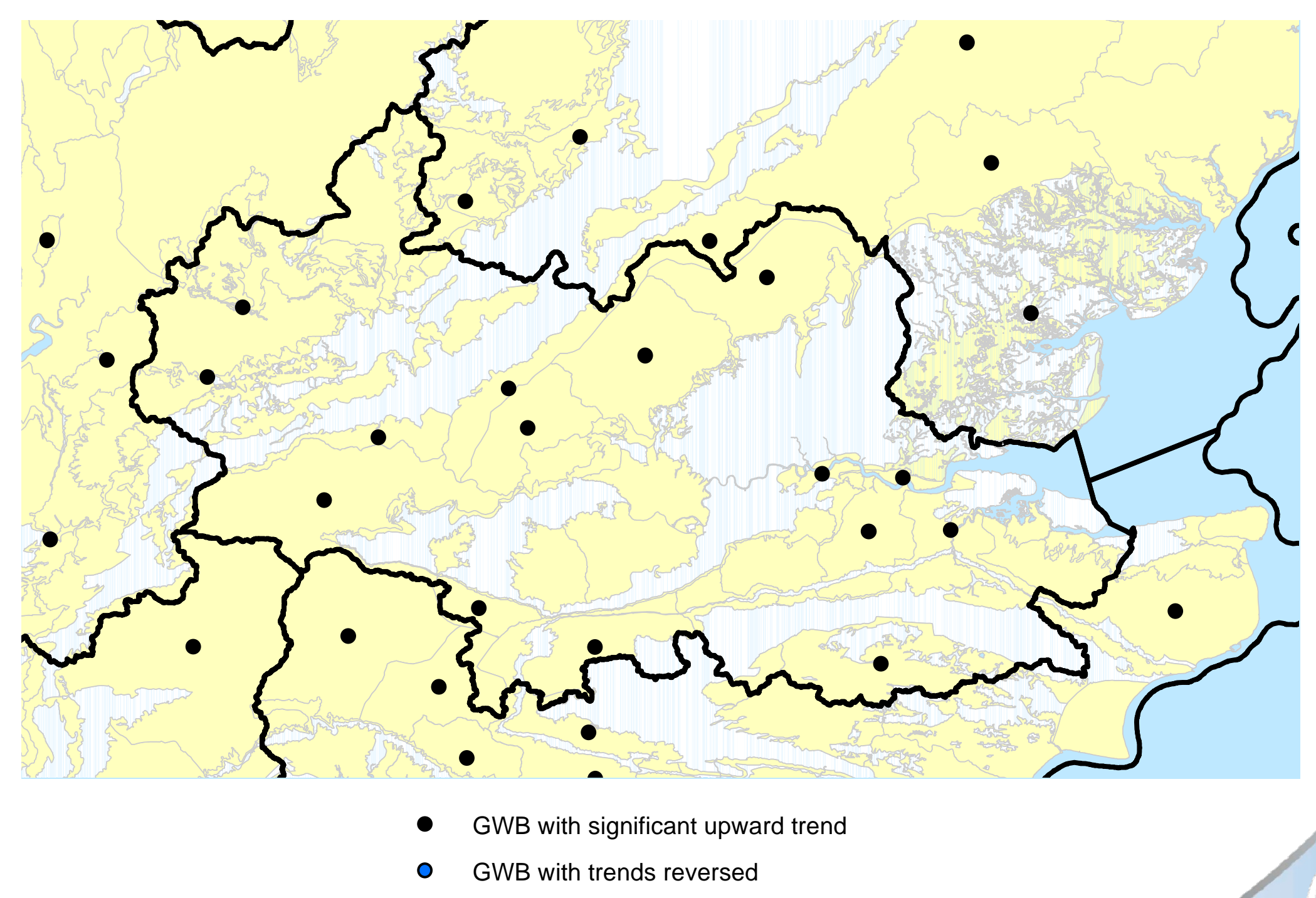




\section{Baseflow index}

- An estimate of the contribution of groundwater to surface flow, taken as a proportion of total streamflow.

- Typically 0.15 to 0.35 for clay catchments

- $>0.9$ for chalk streams

- 0.9 for Jurassic limestone catchments

- 0.65 for Thames in West London

- 0.87 Pang at Pangbourne

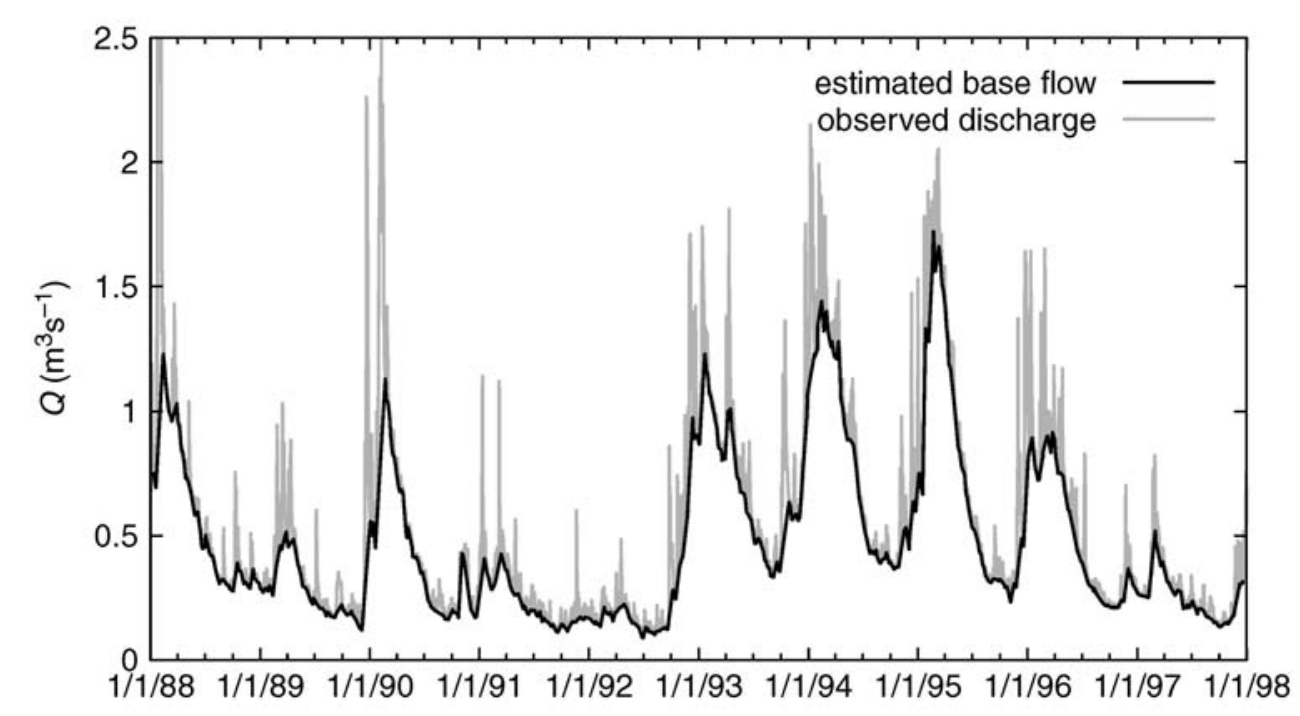

Estimation of baseflow in the Pang at Pangbourne using BFI. From 


\section{Geological and hydrogeological statistical models of baseflow in the Thames Basin}

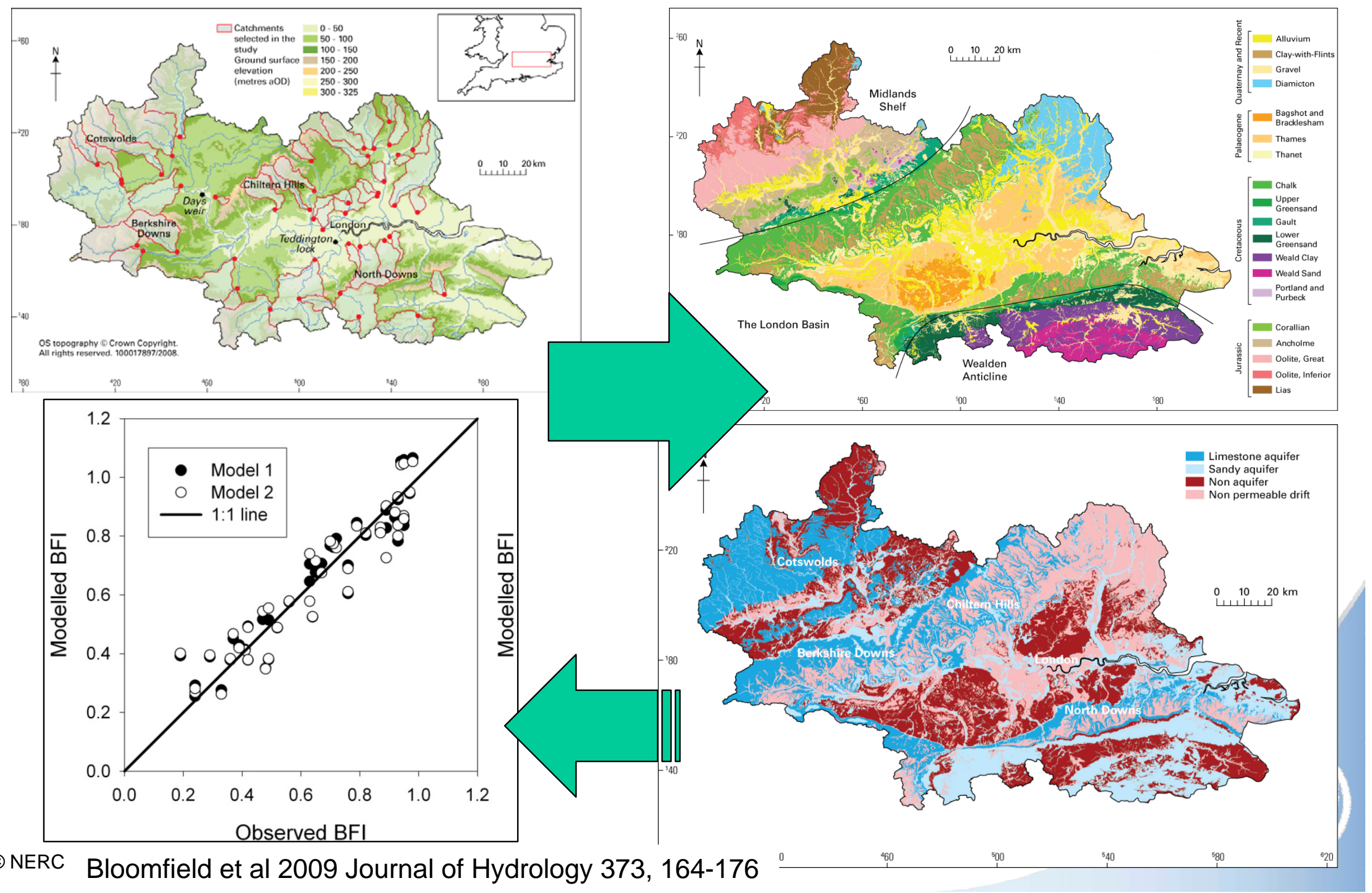




\section{Nitrate in the unsaturated zone}

Model relating:

- Unsaturated zone velocity

- Depth to water

- 1980-90 peak nitrate applications

From Wang et al. 2012, Hydrological

Processes, 26, 236-239
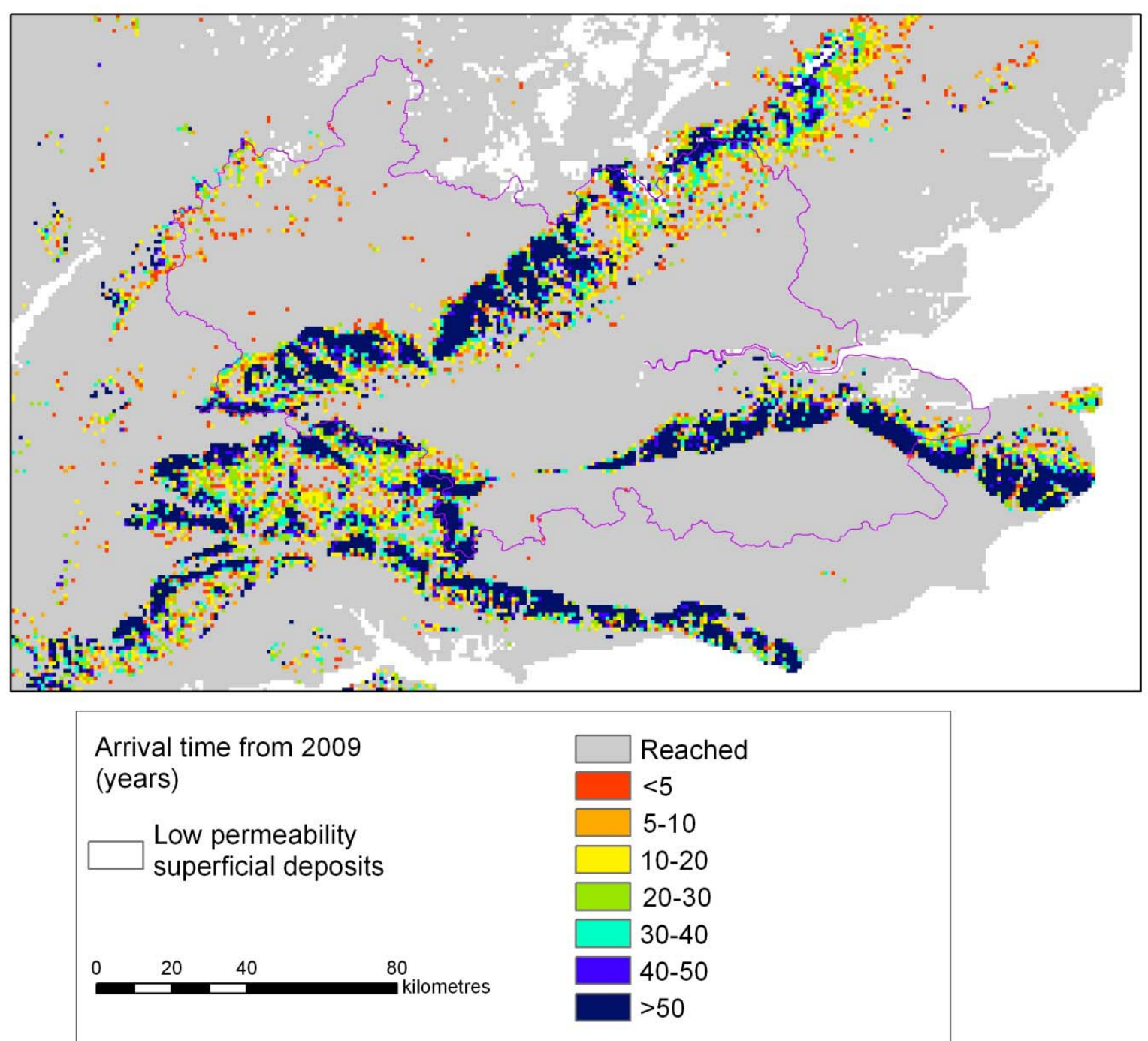


\section{Nitrate flux in Thames catchment}

Nitrate data show:

- Rapid response to landuse change

- Slower component due to groundwater pathway

- Overall limited system

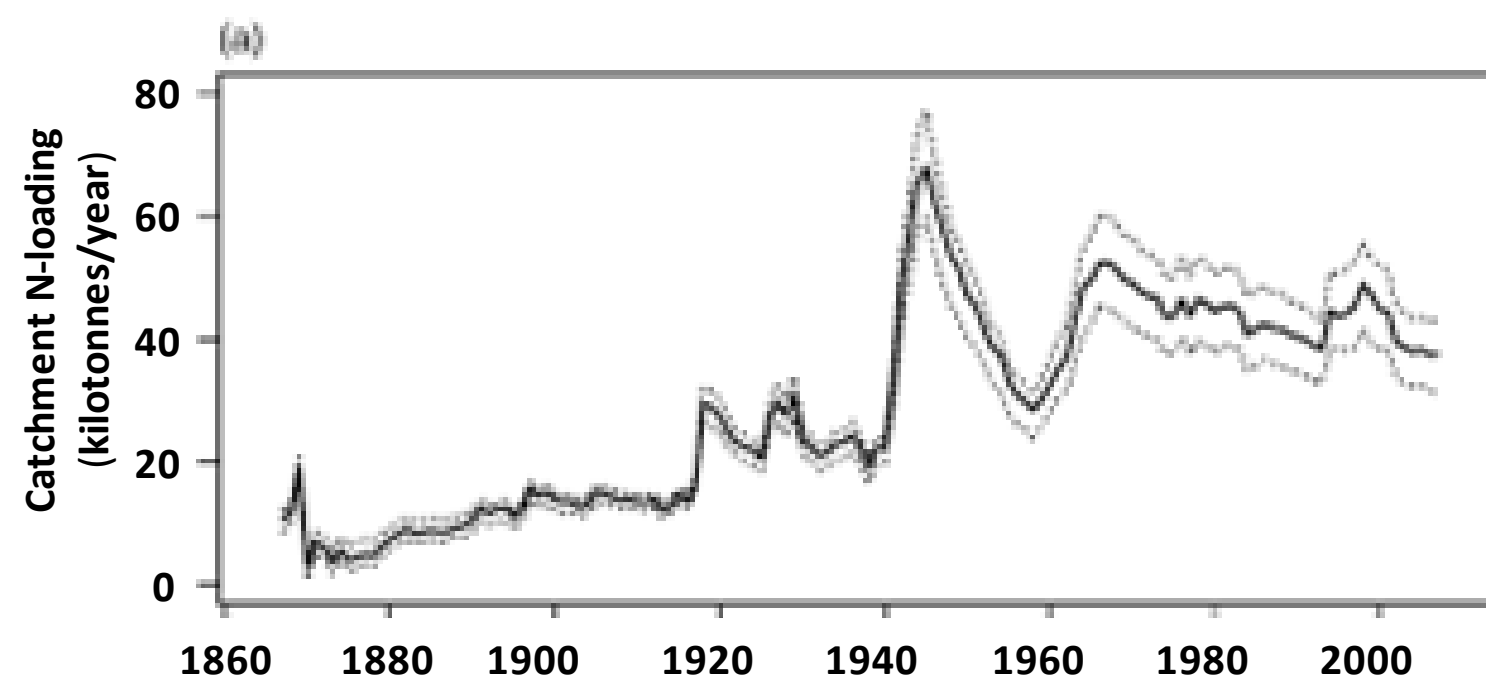
recovery from

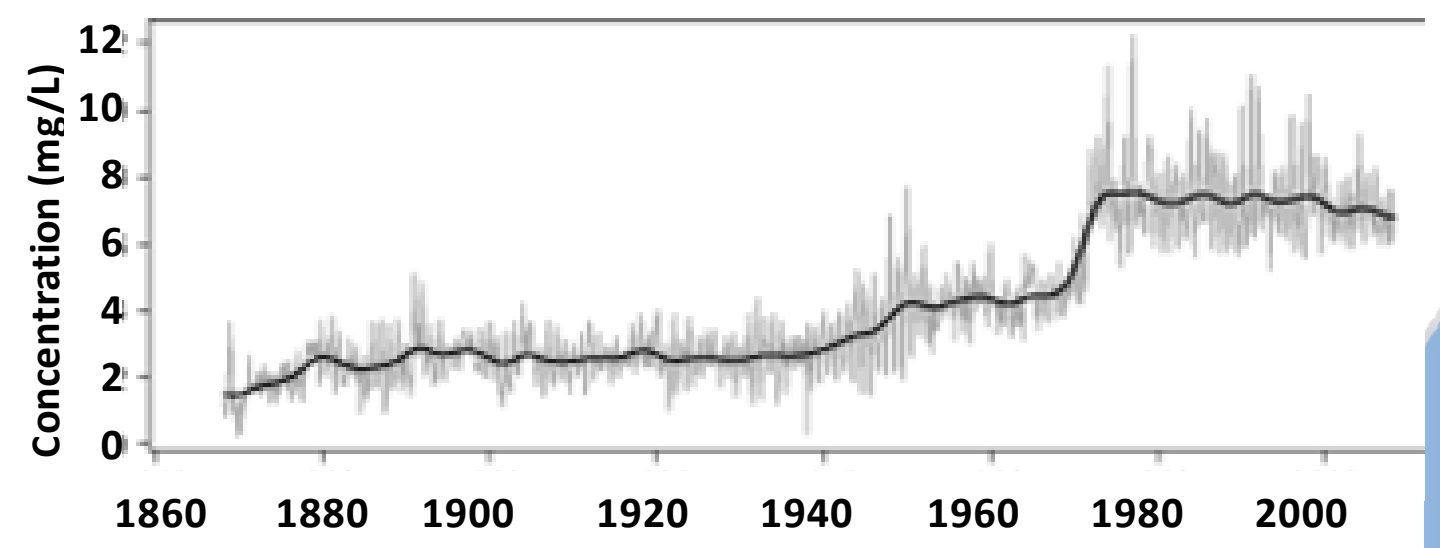




\section{Wetlands}

- Good groundwater chemical status requires that the concentrations of pollutants in groundwater would not cause significant damage to the ecological quality of a surface water body or to a terrestrial ecosystem, such as a wetland
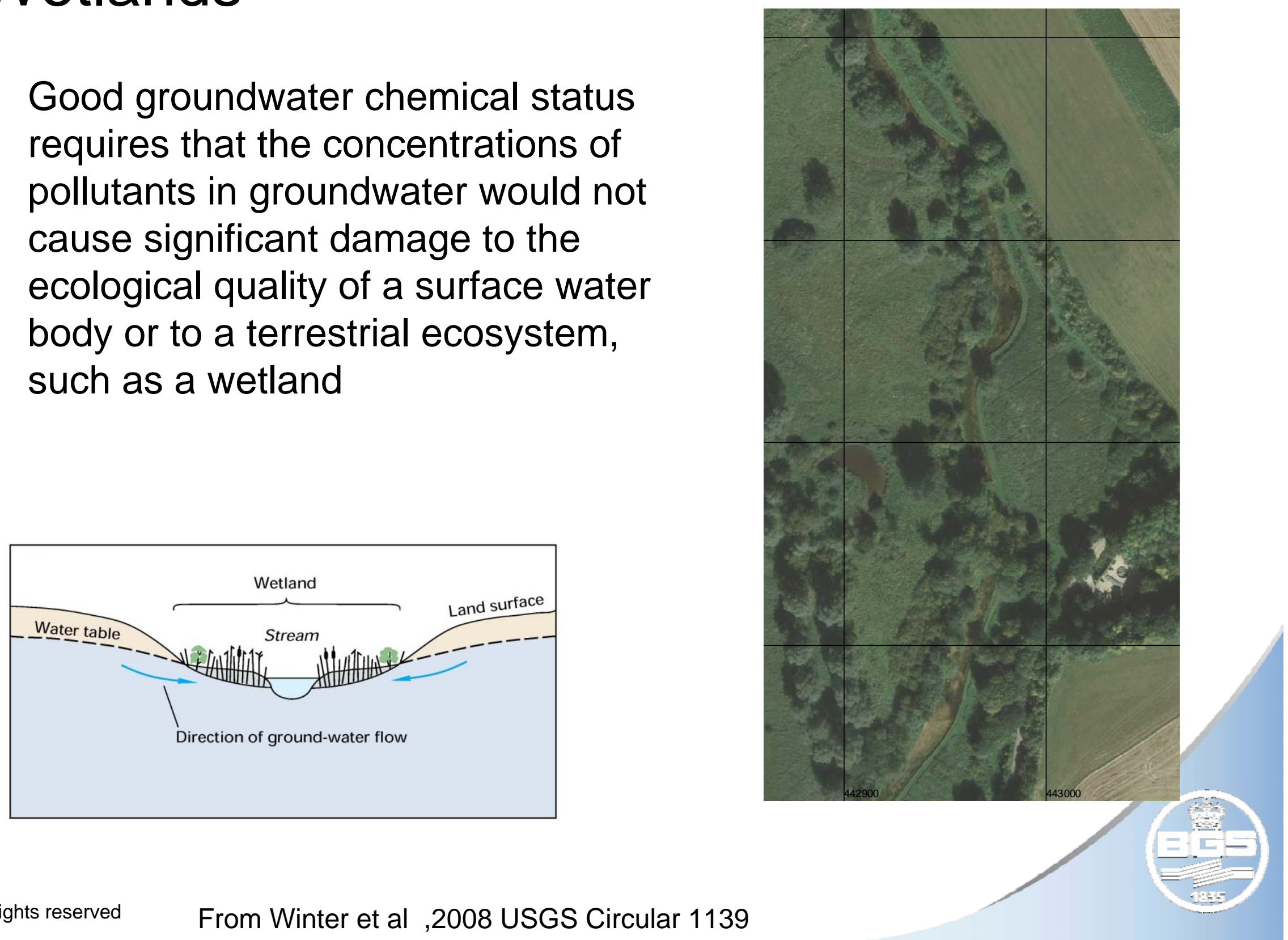


\section{Hyporheic zone}

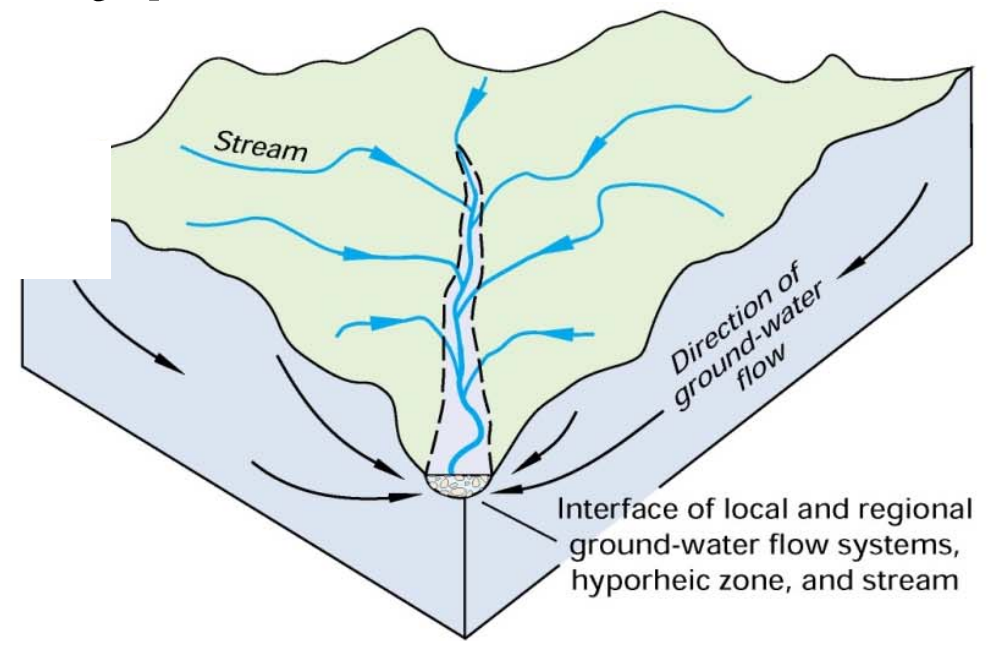

From Winter et al ,2008

USGS Circular 1139

- Exchanges of water, nutrients and organic matter

- Microscale gradients in redox potential and nutrient transformations

- Stream scale gradients in faunal composition, uptake of organic carbon and nitrification

- Catchment scale hyporheic corridor possible $\mathrm{km}$ from main channel

- To understand nutrient movement we need to understand residence time, multiple flow paths and hydraulic reversal

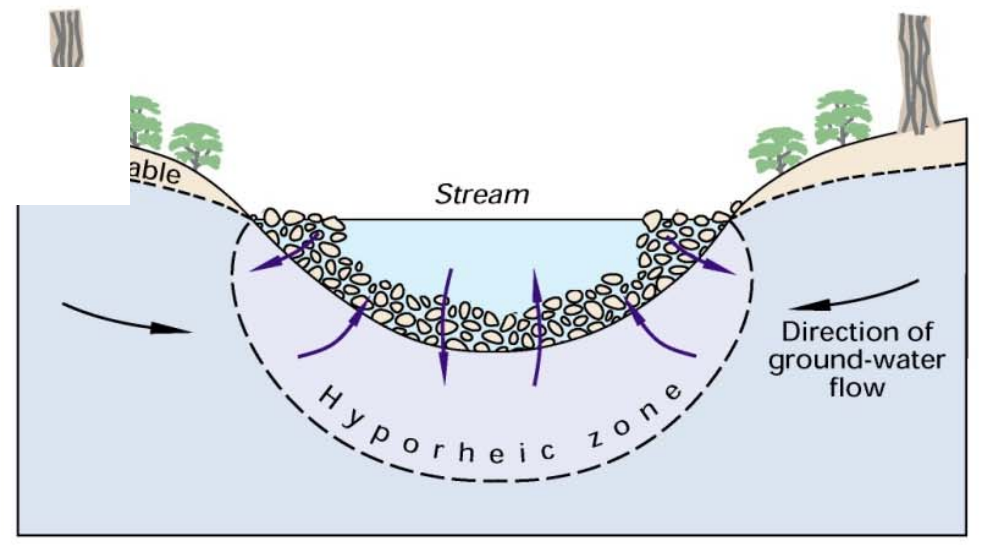




\section{Boxford}

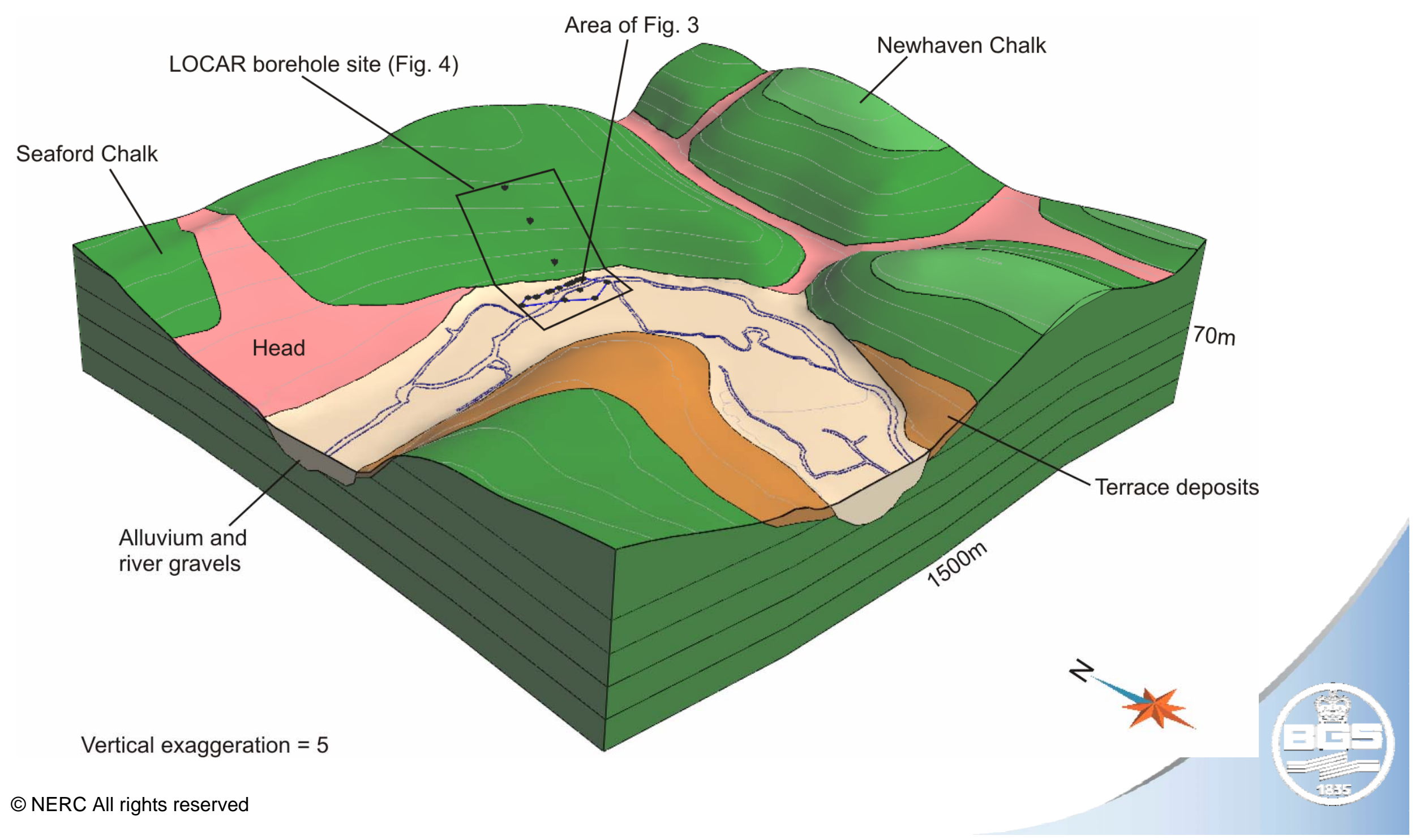




\section{Hydraulic reversal}

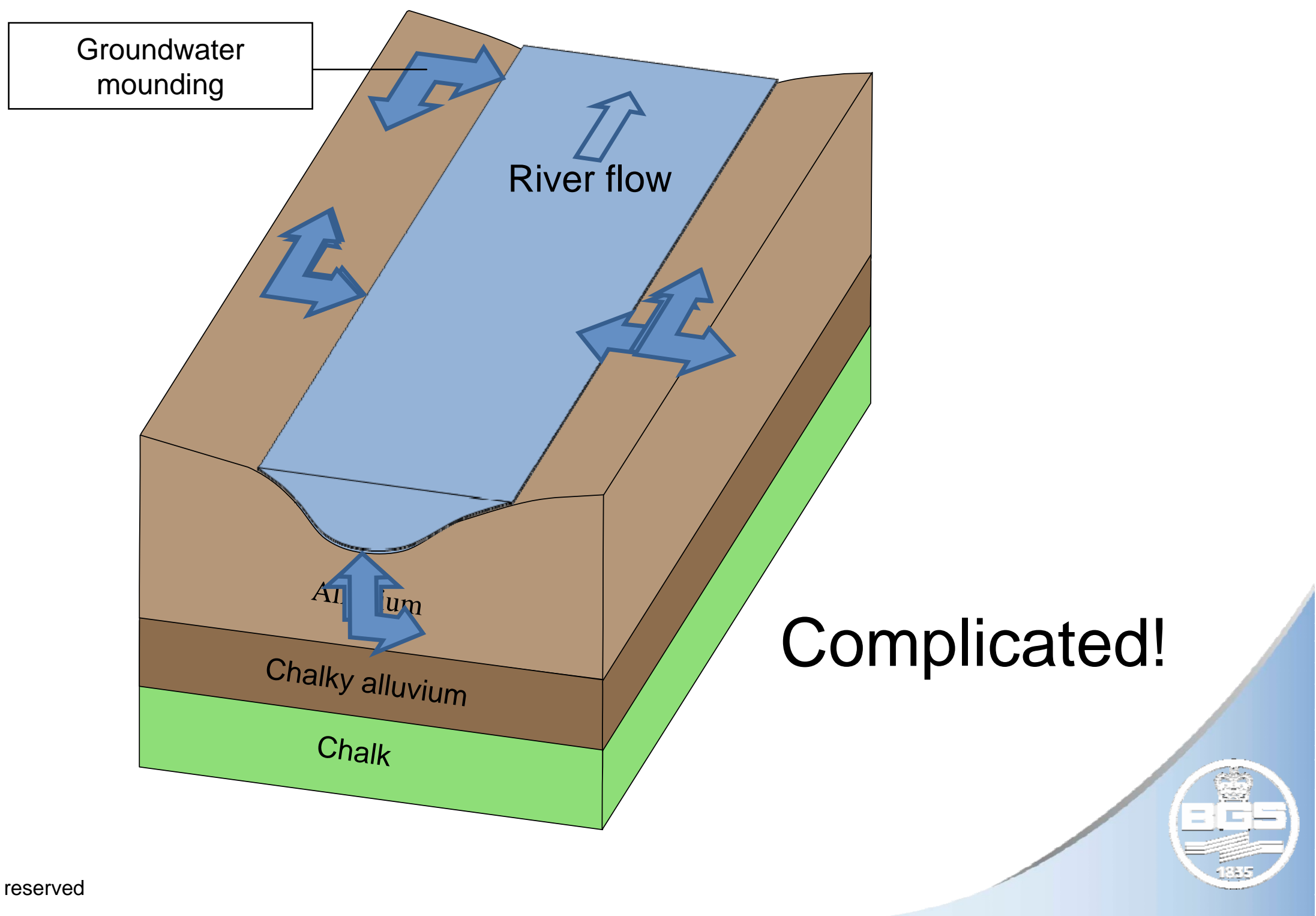




\section{Using fluorescence to show gw/sw interaction}

Shows much better connectivity with the river, $\mathrm{E}>\mathrm{D}$

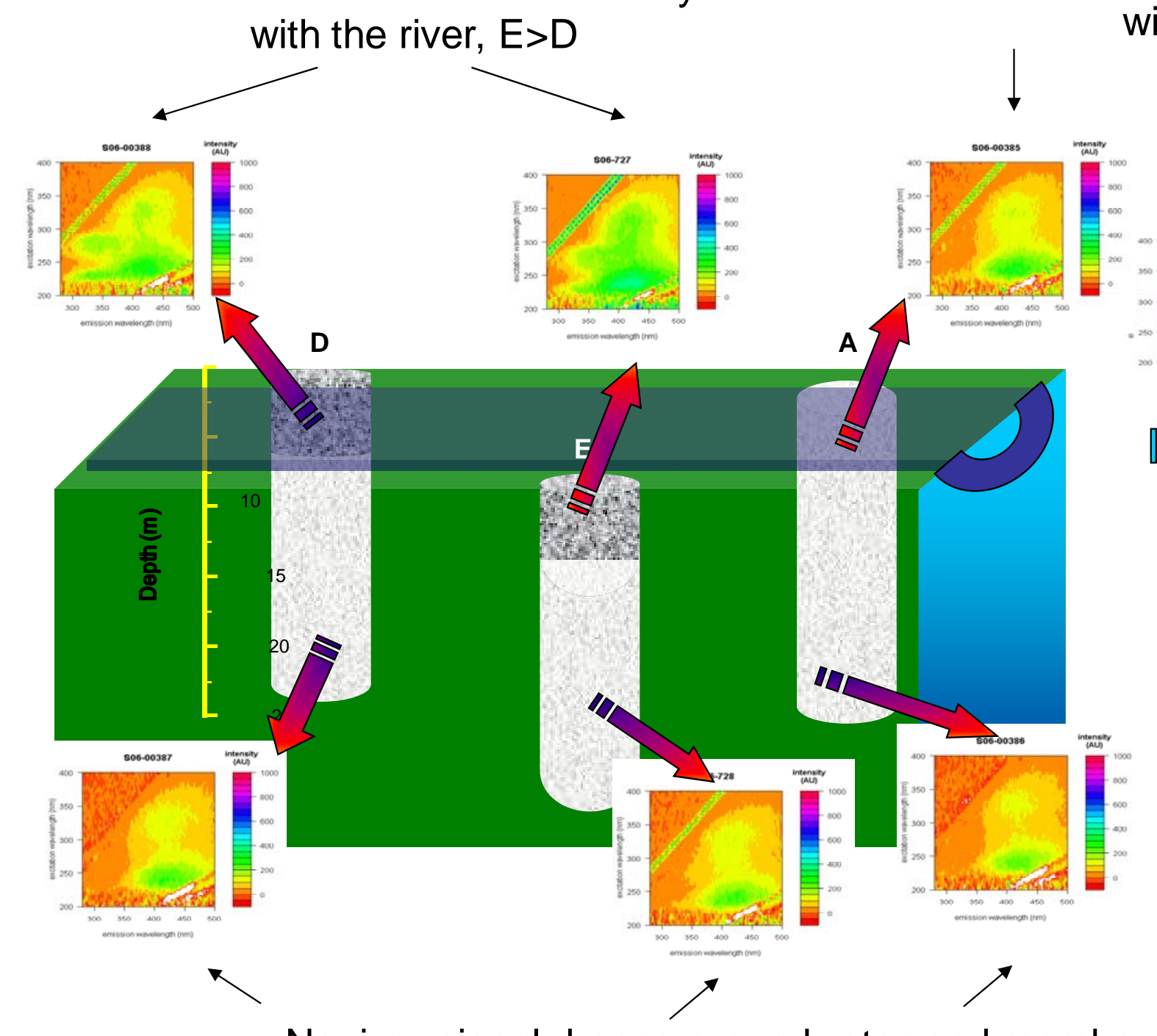

No river signal, hence groundwater end member ( ) NERC All rights reserved

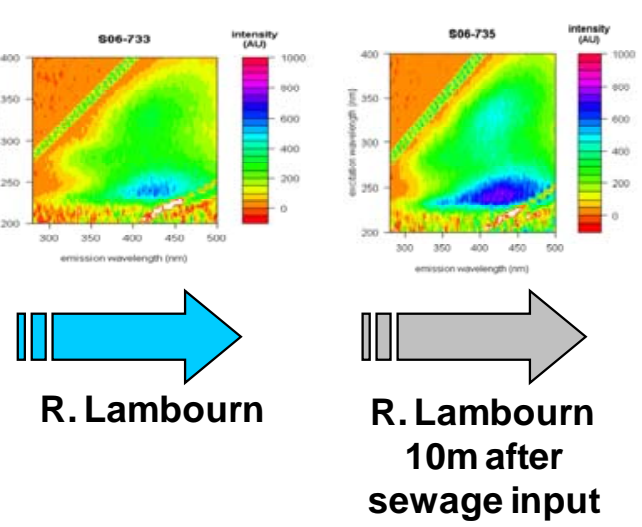

Key

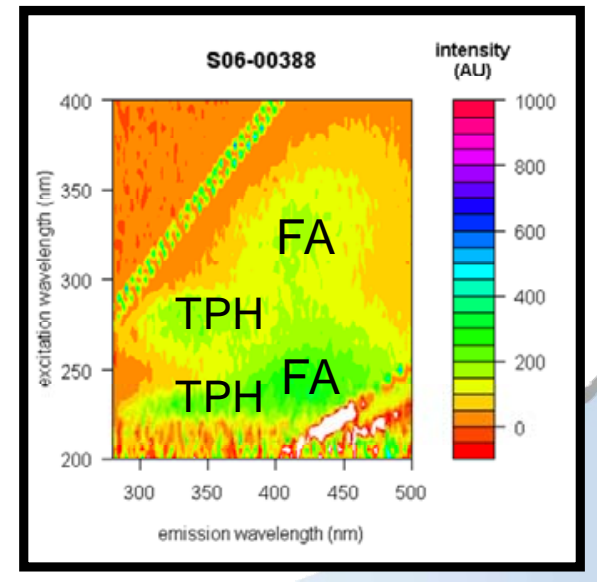




\section{Farm impact}
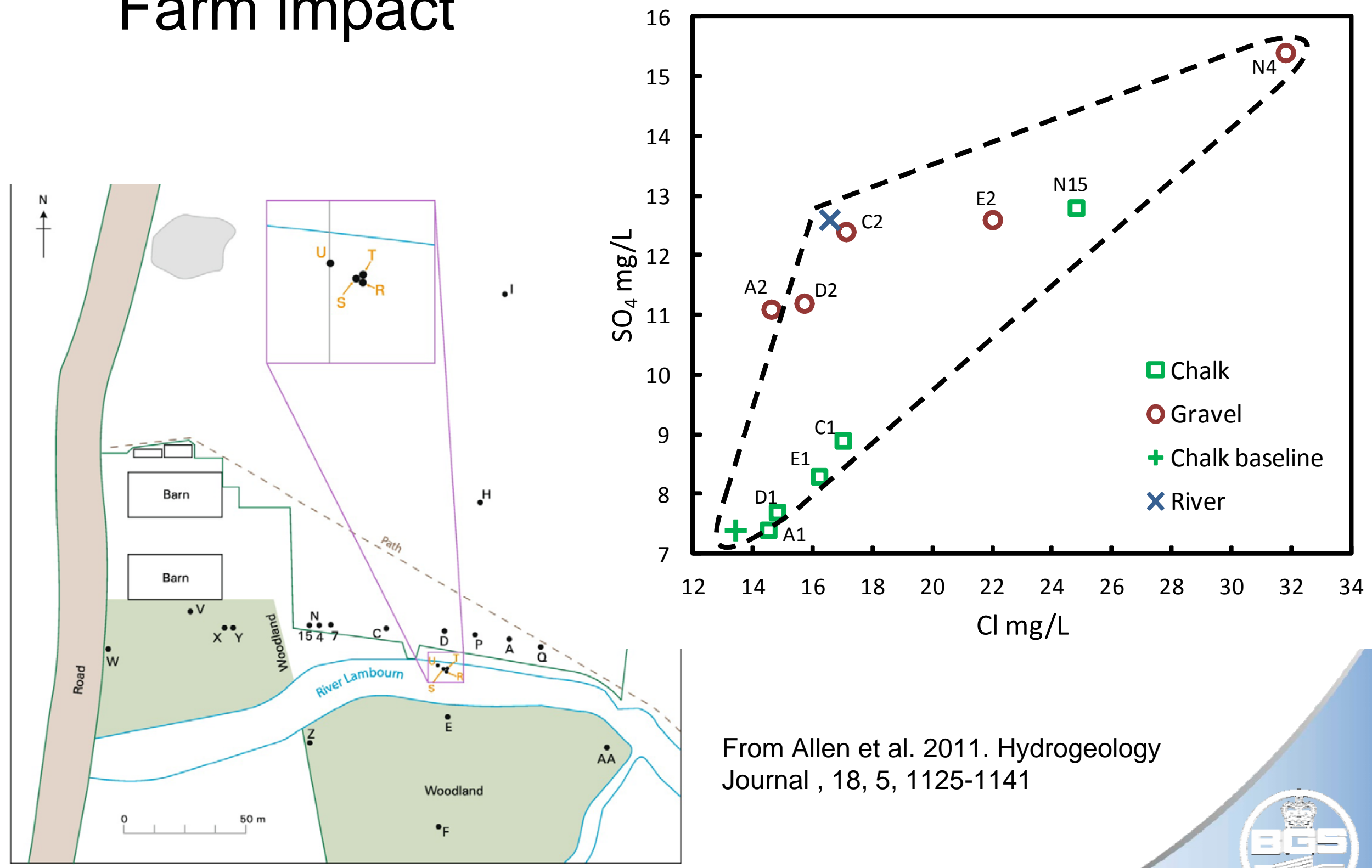

From Allen et al. 2011. Hydrogeology

Journal , 18, 5, 1125-1141 


\section{Floodplains}

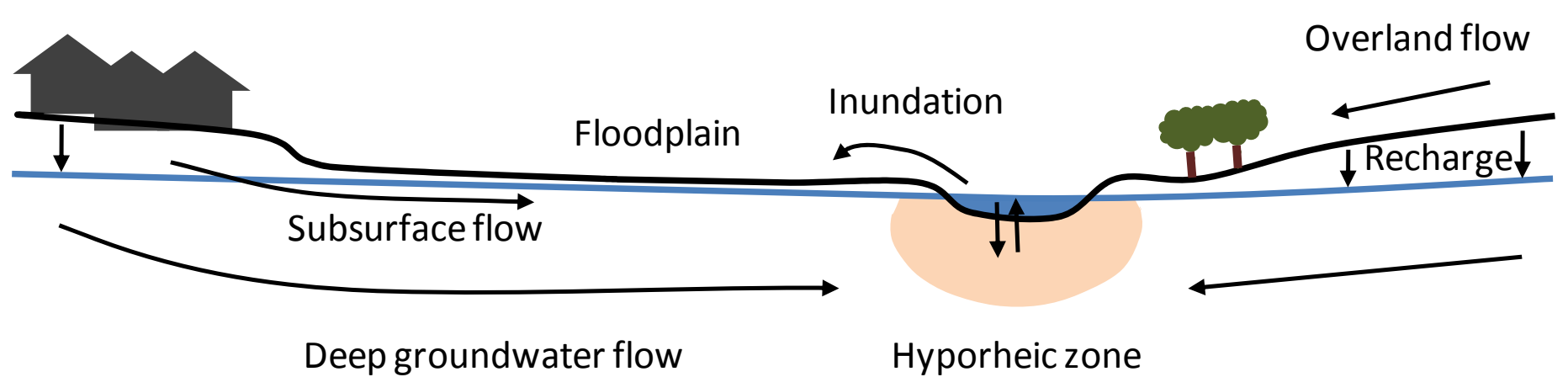

- Collection point for groundwater, overland flow and river water

- Dynamic environment - shallow fluctuating water table, flood inundation, reversal in gradient

- Exchanges of water and nutrients

- Redox spatially and temporally variable

- Significant denitrification but P accumulation

- For many other contaminants may be significant natural remediation

- Implications for attenuation of groundwater pollutants and discharge to rivers 


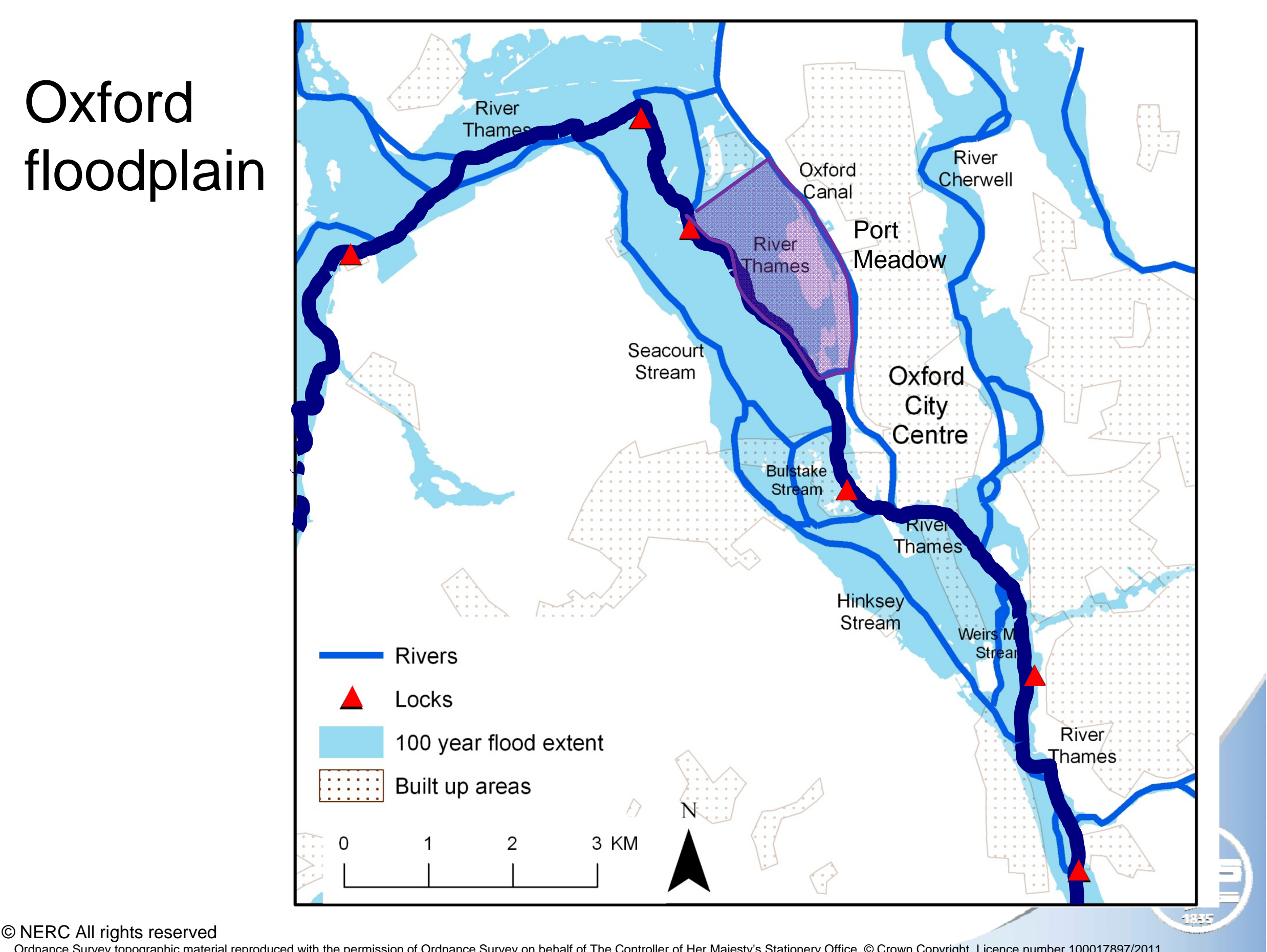

Ordnance Survey topographic material reproduced with the permission of Ordnance Survey on behalf of The Controller of Her Majesty's Stationery Office, ๑ Crown Copyright. Licence number 100017897/2011. 


\section{Port Meadow research site}

- On Thames floodplain west of Oxford

- Urban area, old landfill, agriculture

- Dynamic environment - shallow fluctuating water table, flood inundation, reversal in gradient

- Implications for attenuation of groundwater pollutants and discharge to rivers

W

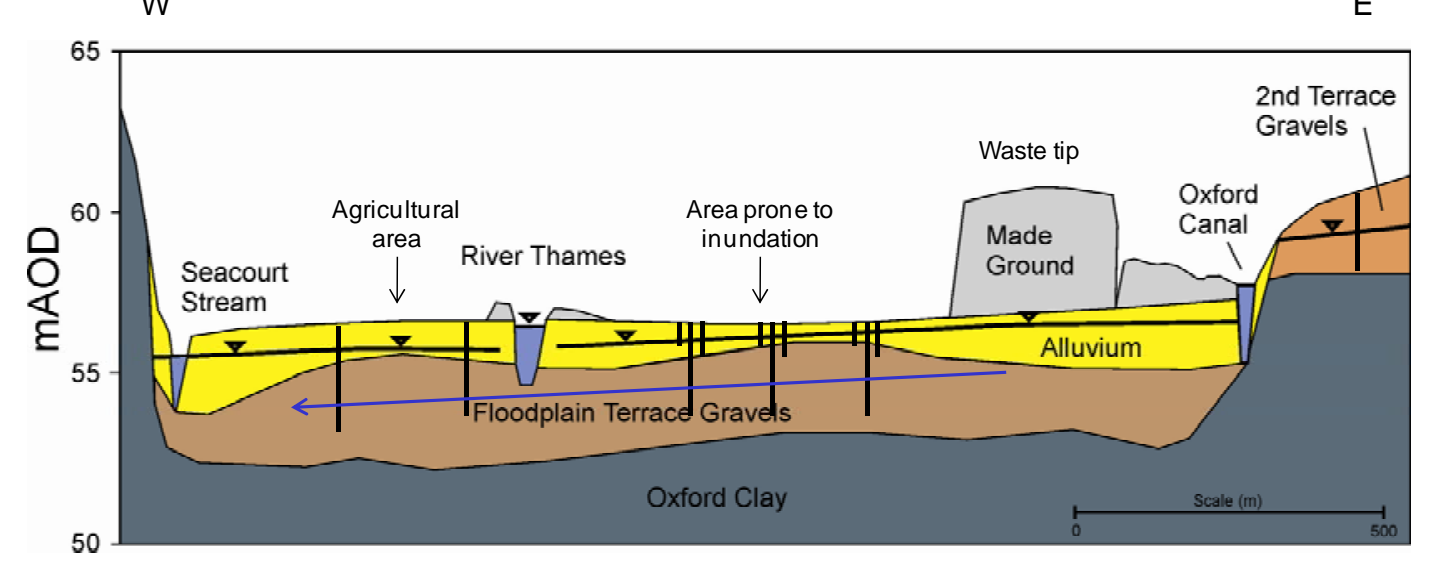

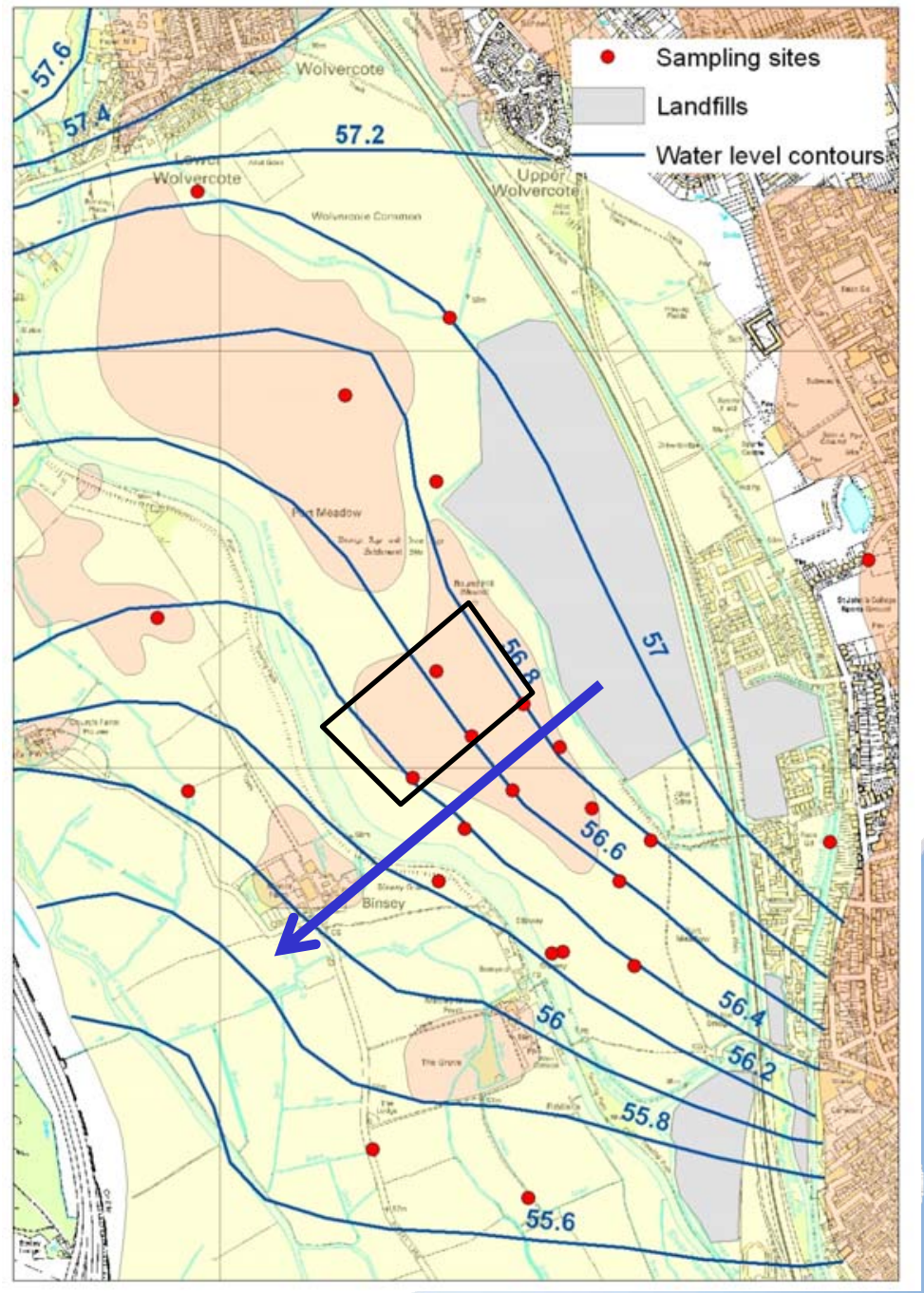




\section{Water quality in Port Meadow}

- Flow is to SE towards Seacourt Stream

- Groundwater predominantly reducing - nitrate removal

- Impact of landfill leachate plume from $\mathrm{Cl}, \mathrm{HCO}_{3}$ etc

- Inundated areas

- Microorganics fingerprint different types of water
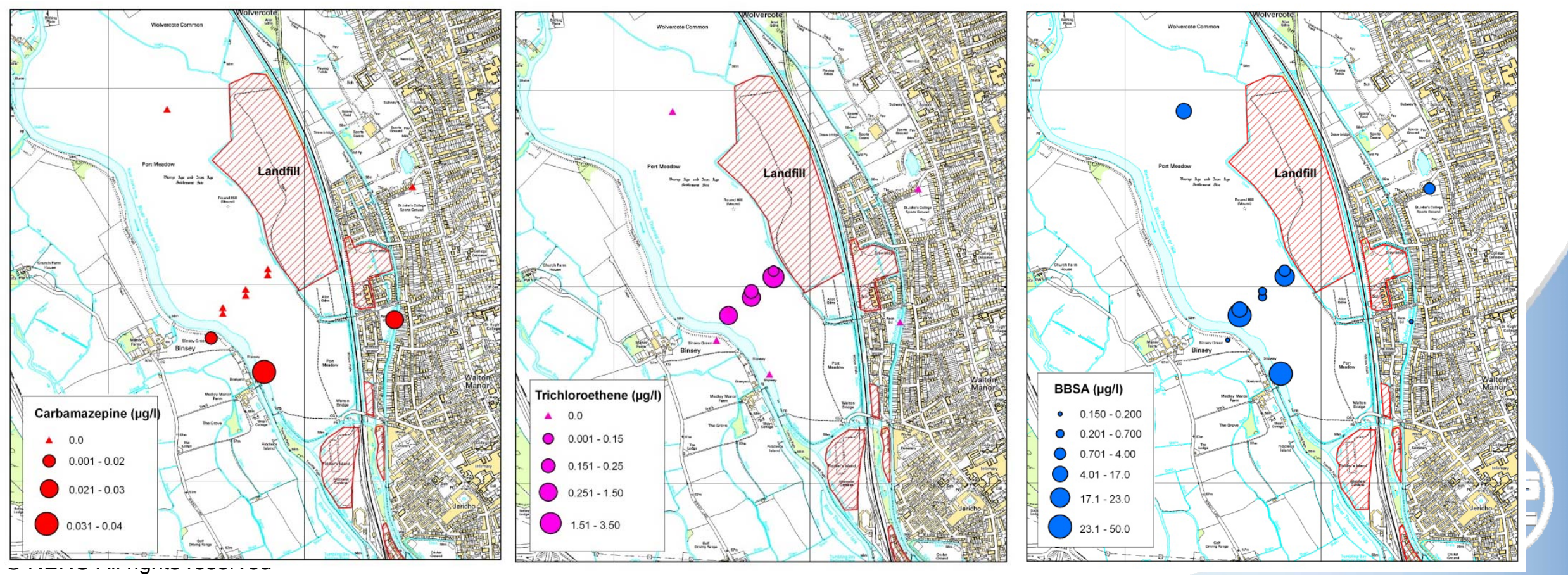


\section{Water levels at Port Meadow}

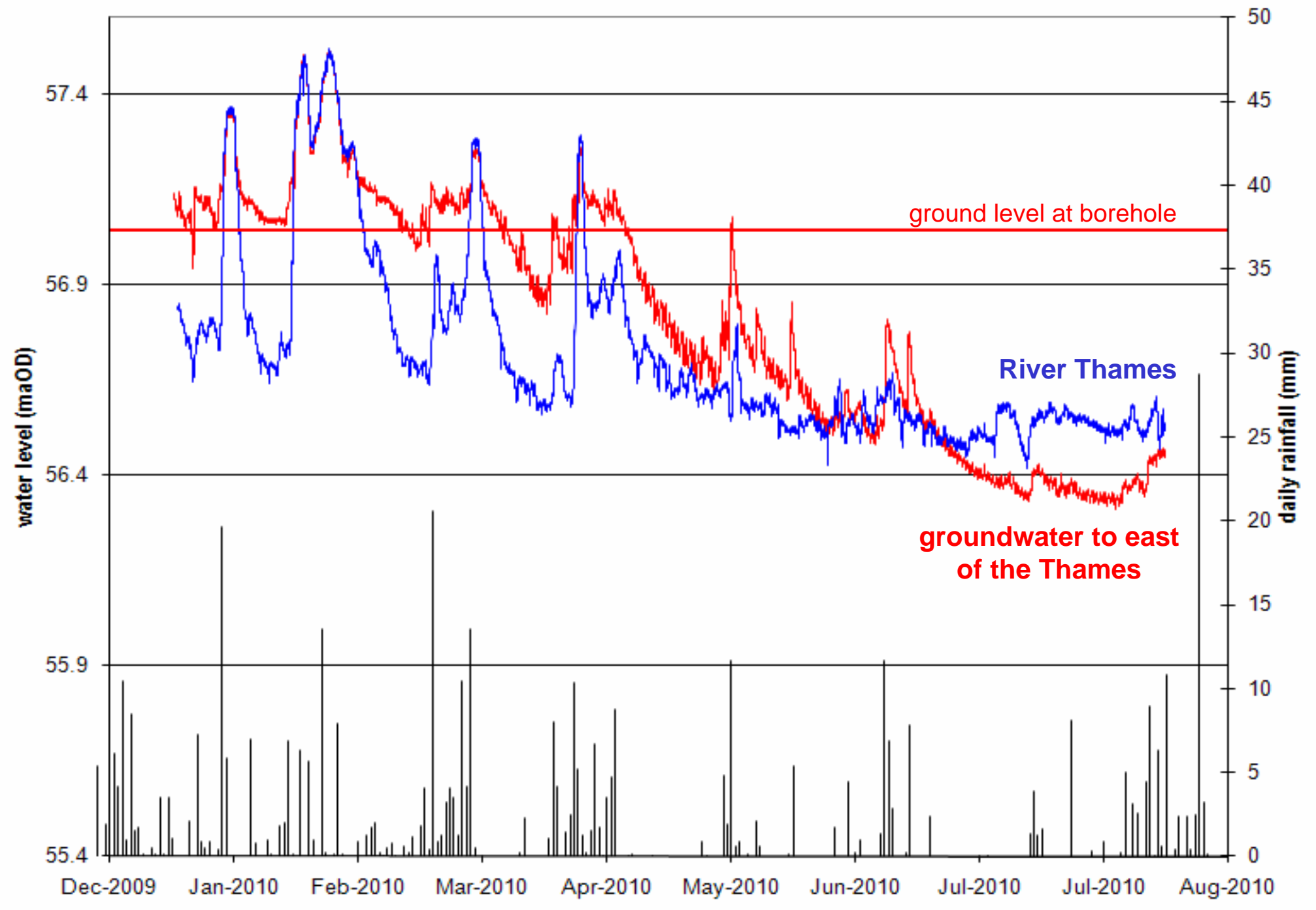




\section{Topography and water levels}
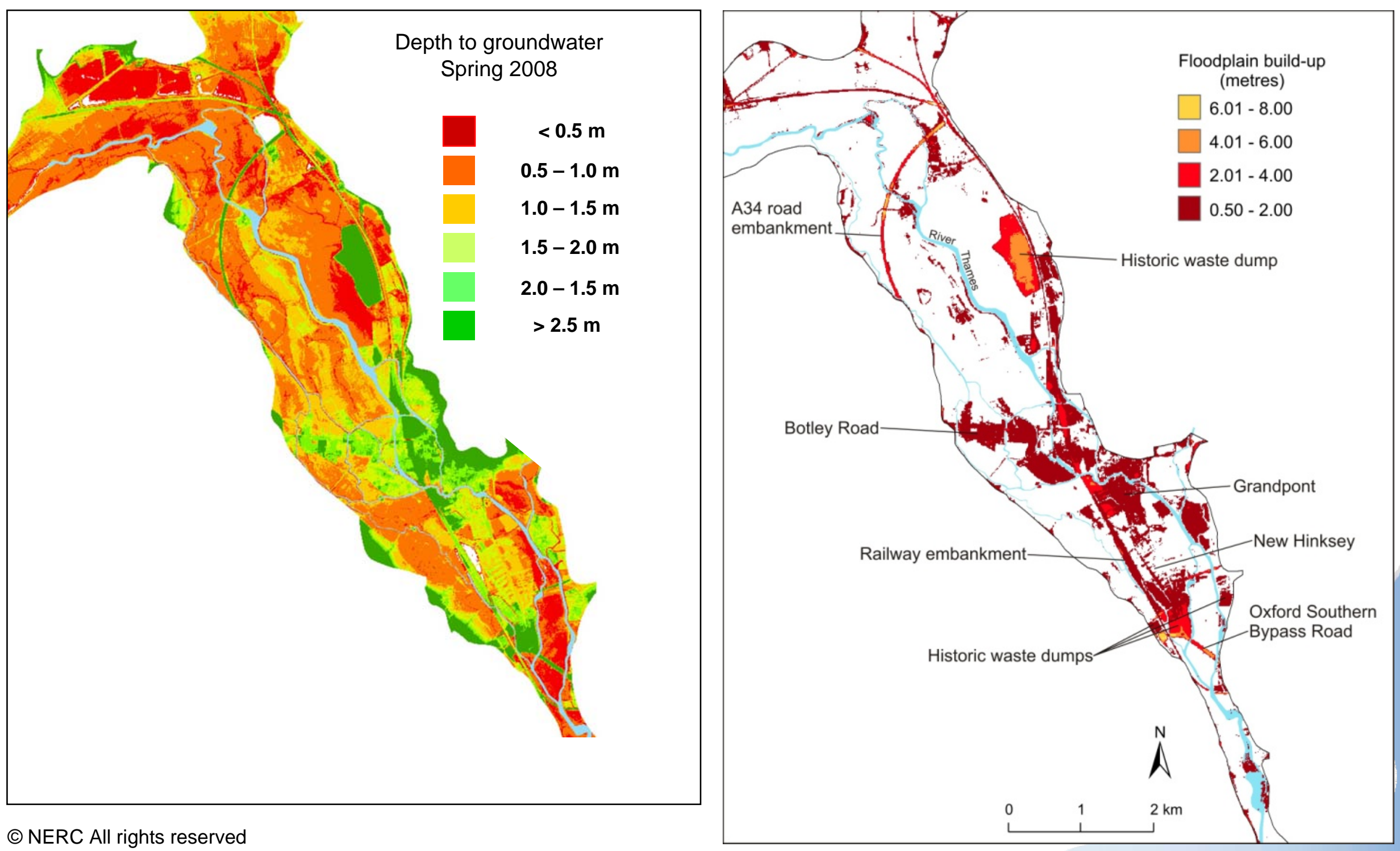


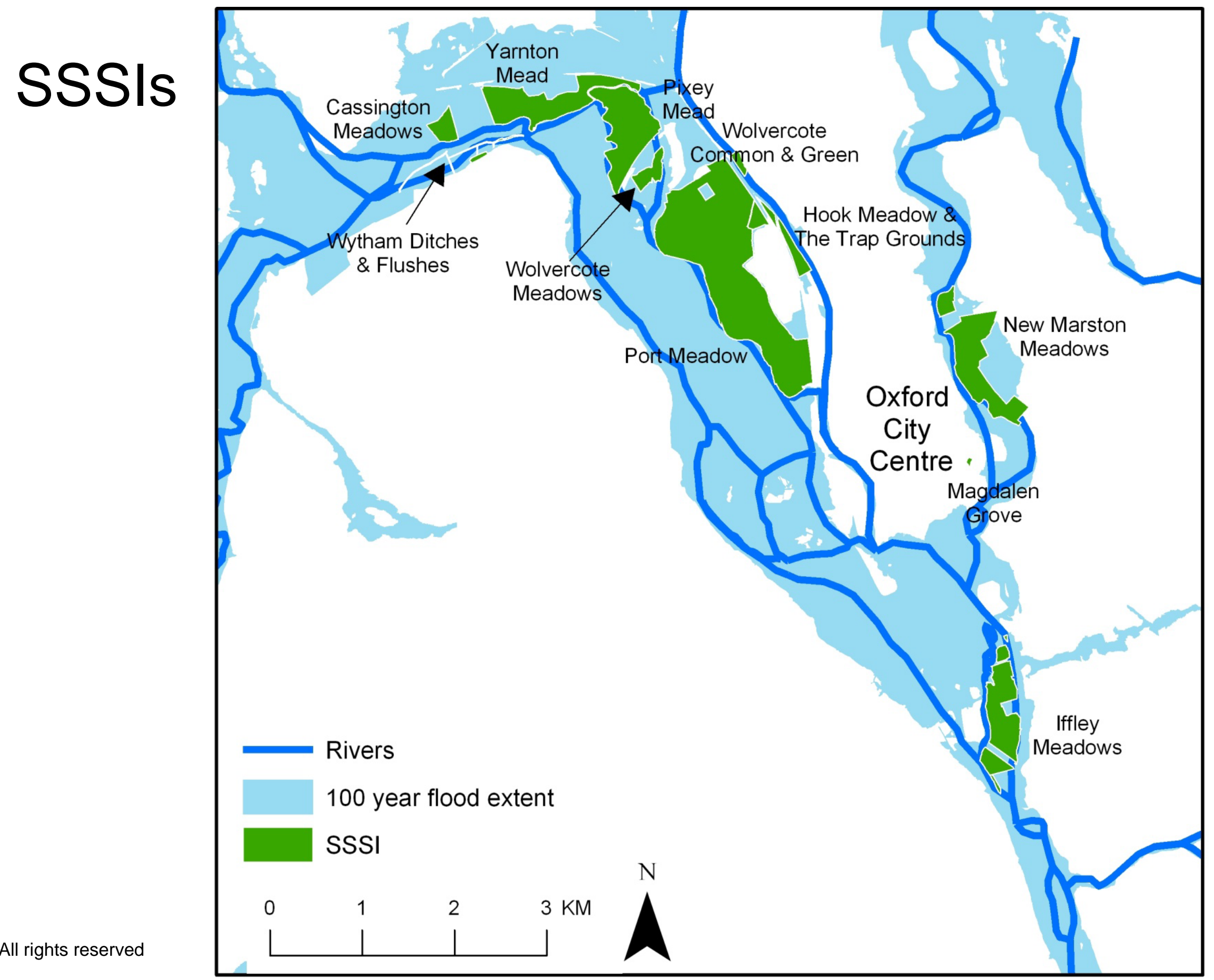




\section{Peak flood water elevation}

July 2007

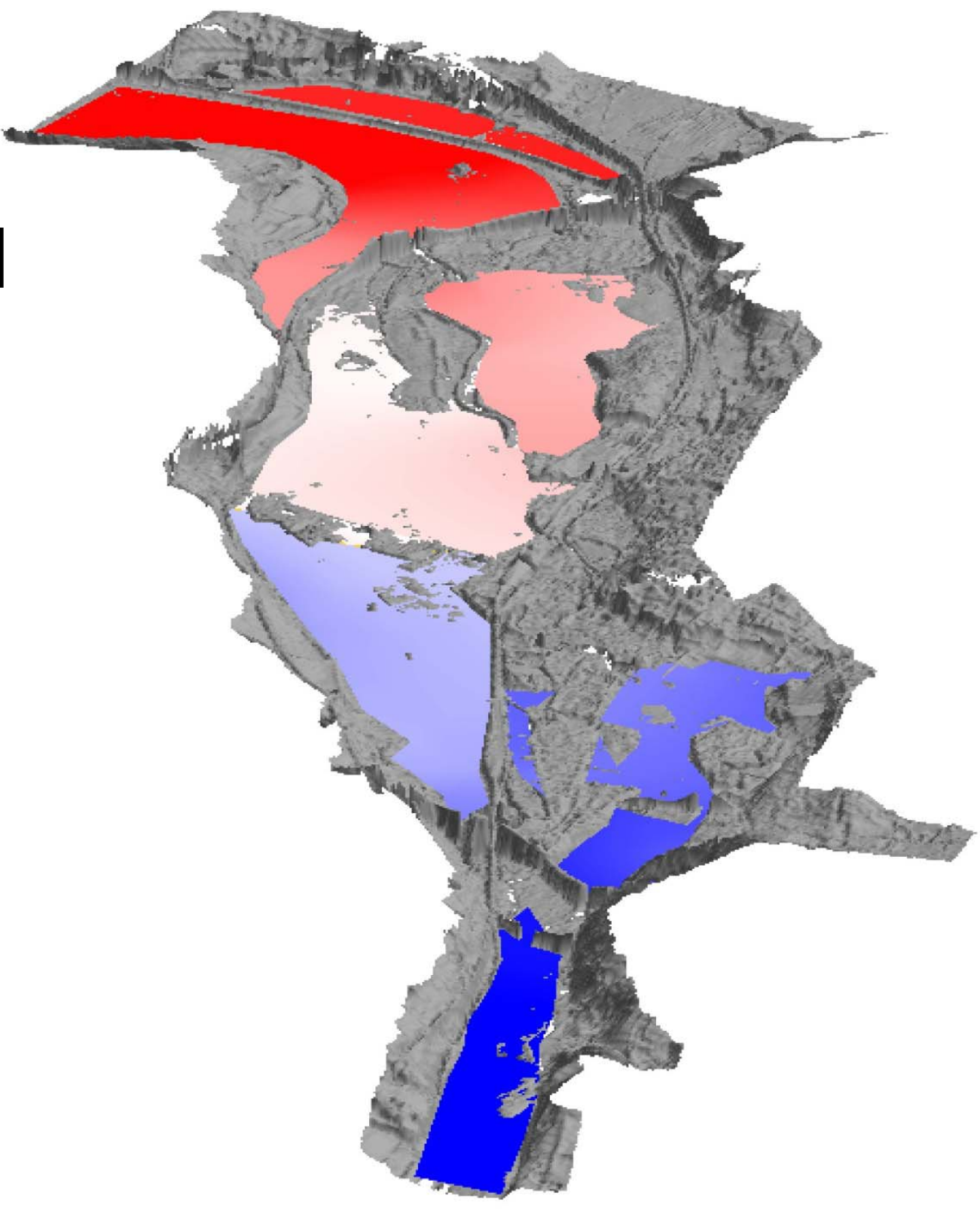

55 


\section{Conceptual model Oxford flooding}

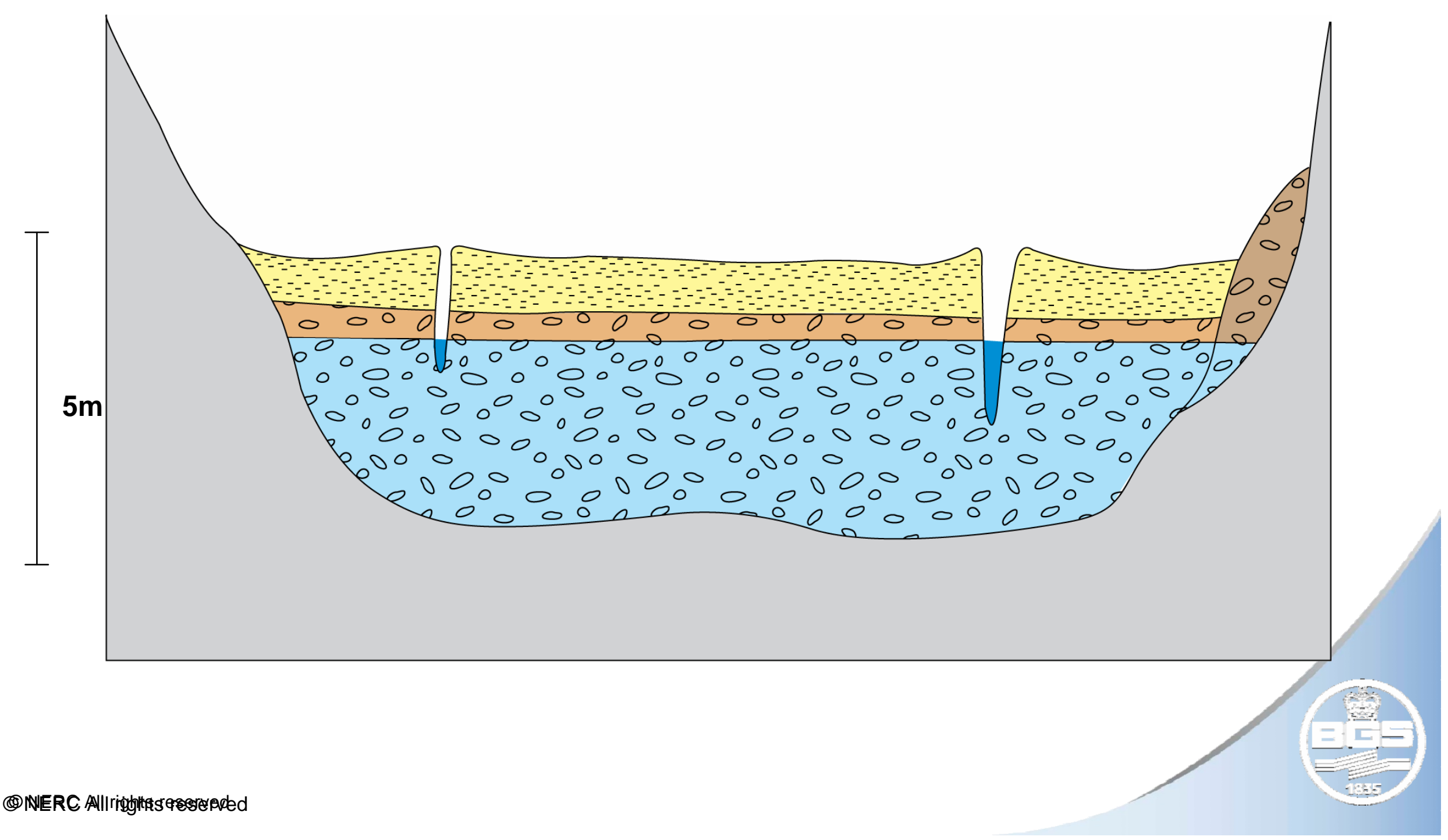




\section{Conceptual model Oxford flooding}

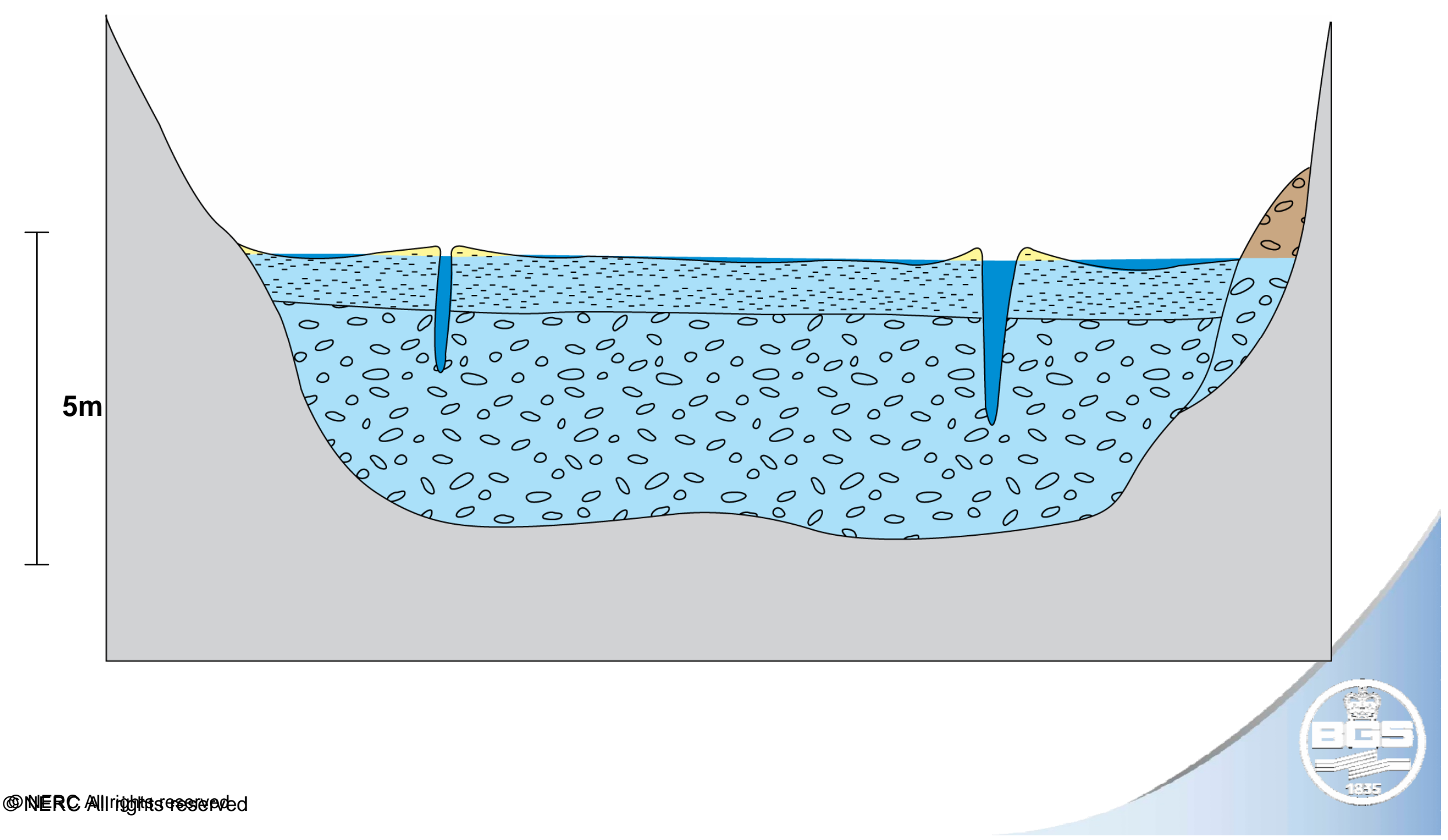




\section{Conceptual model Oxford flooding}

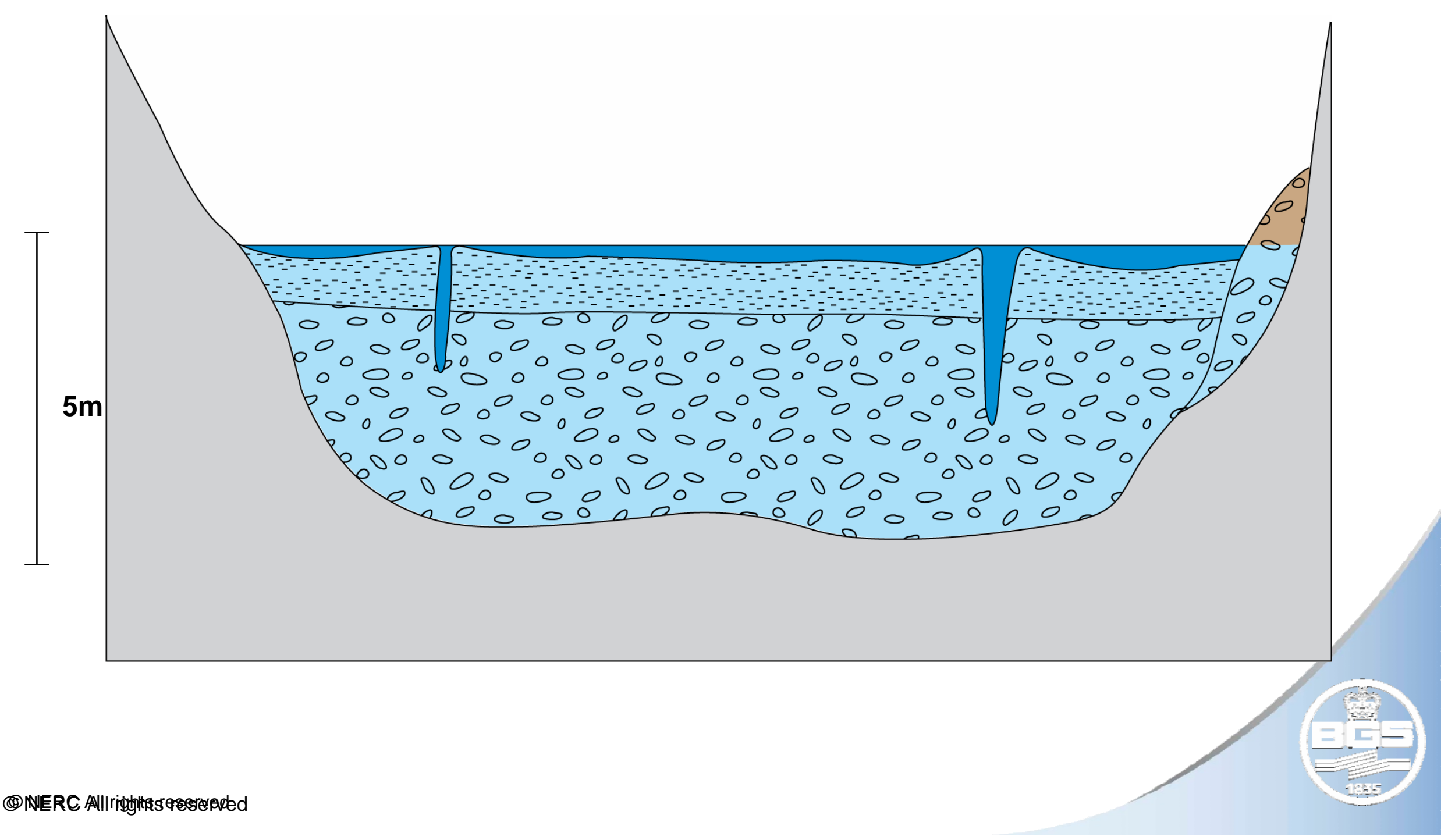




\section{Conceptual model Oxford flooding}

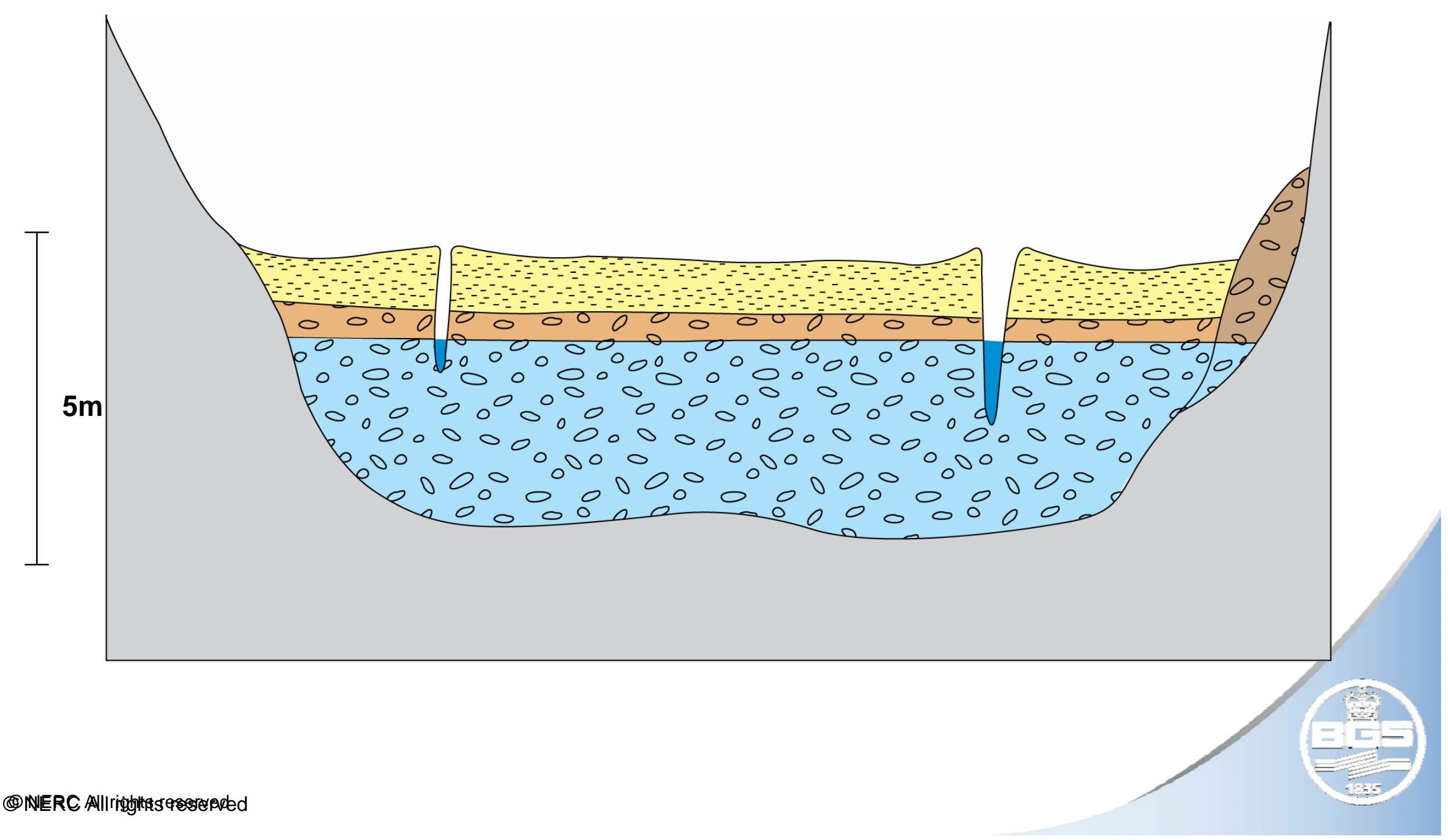




\section{Conceptual model Oxford flooding}

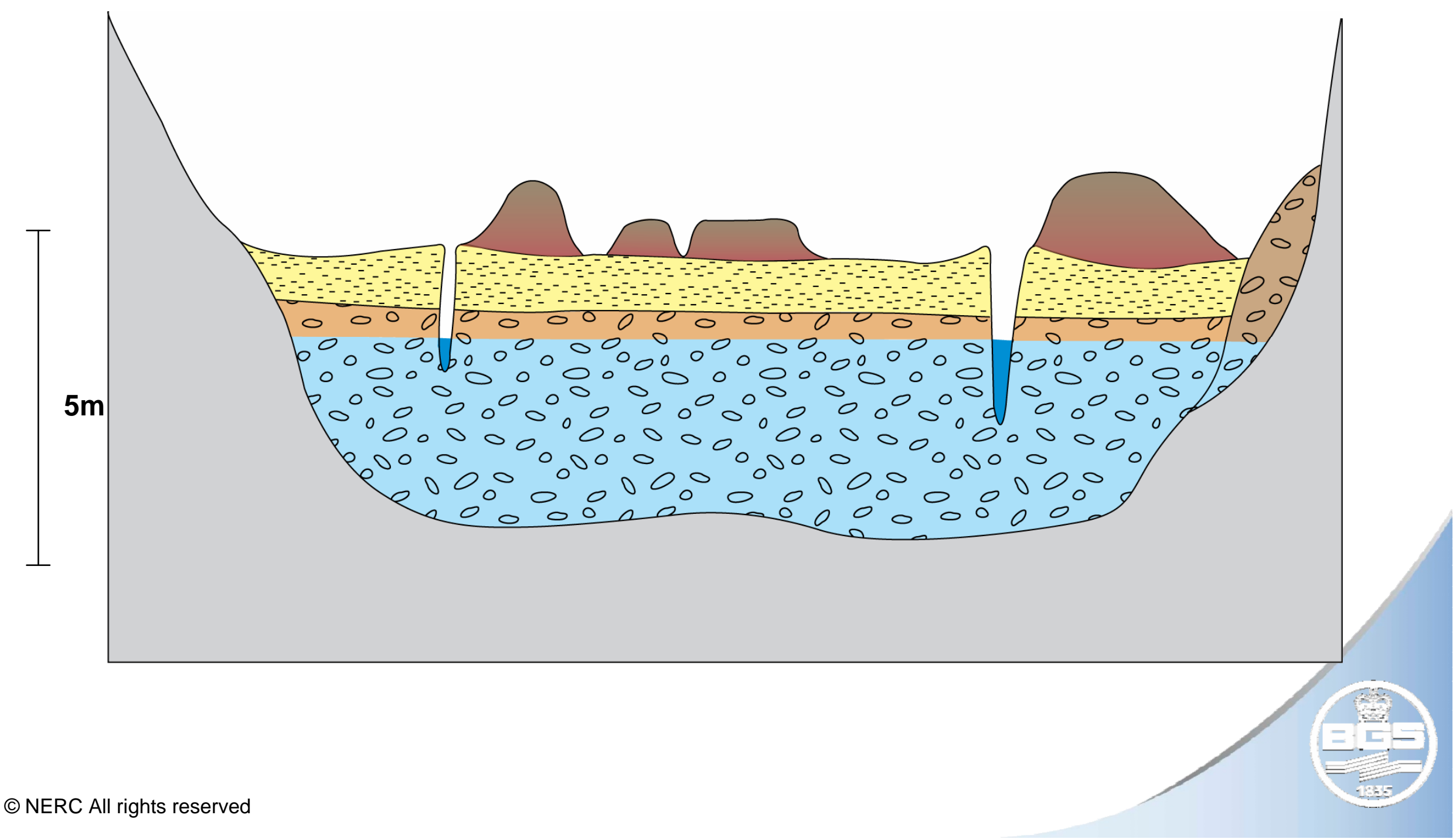




\section{Conceptual model Oxford flooding}

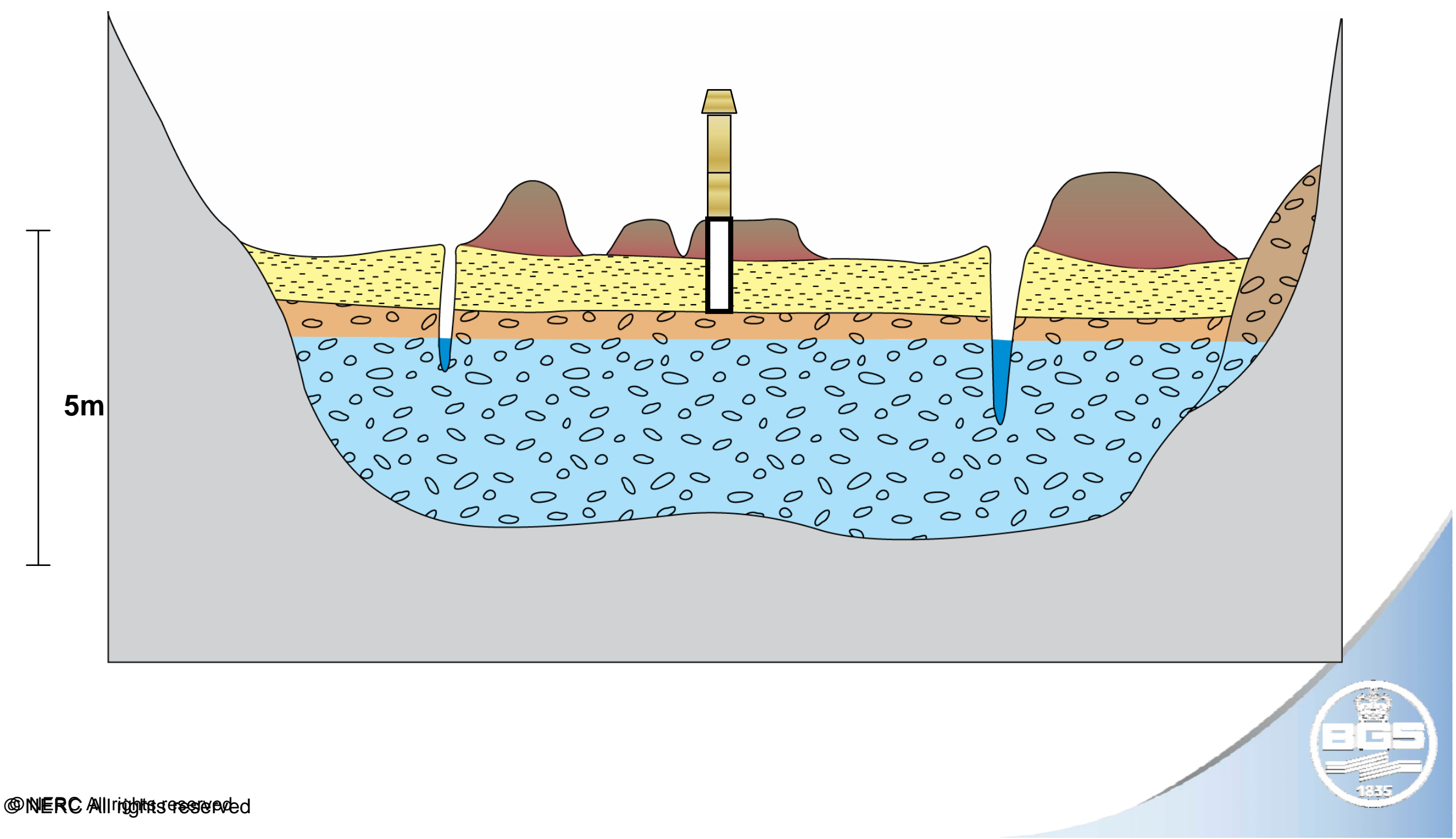




\section{Conceptual model Oxford flooding}

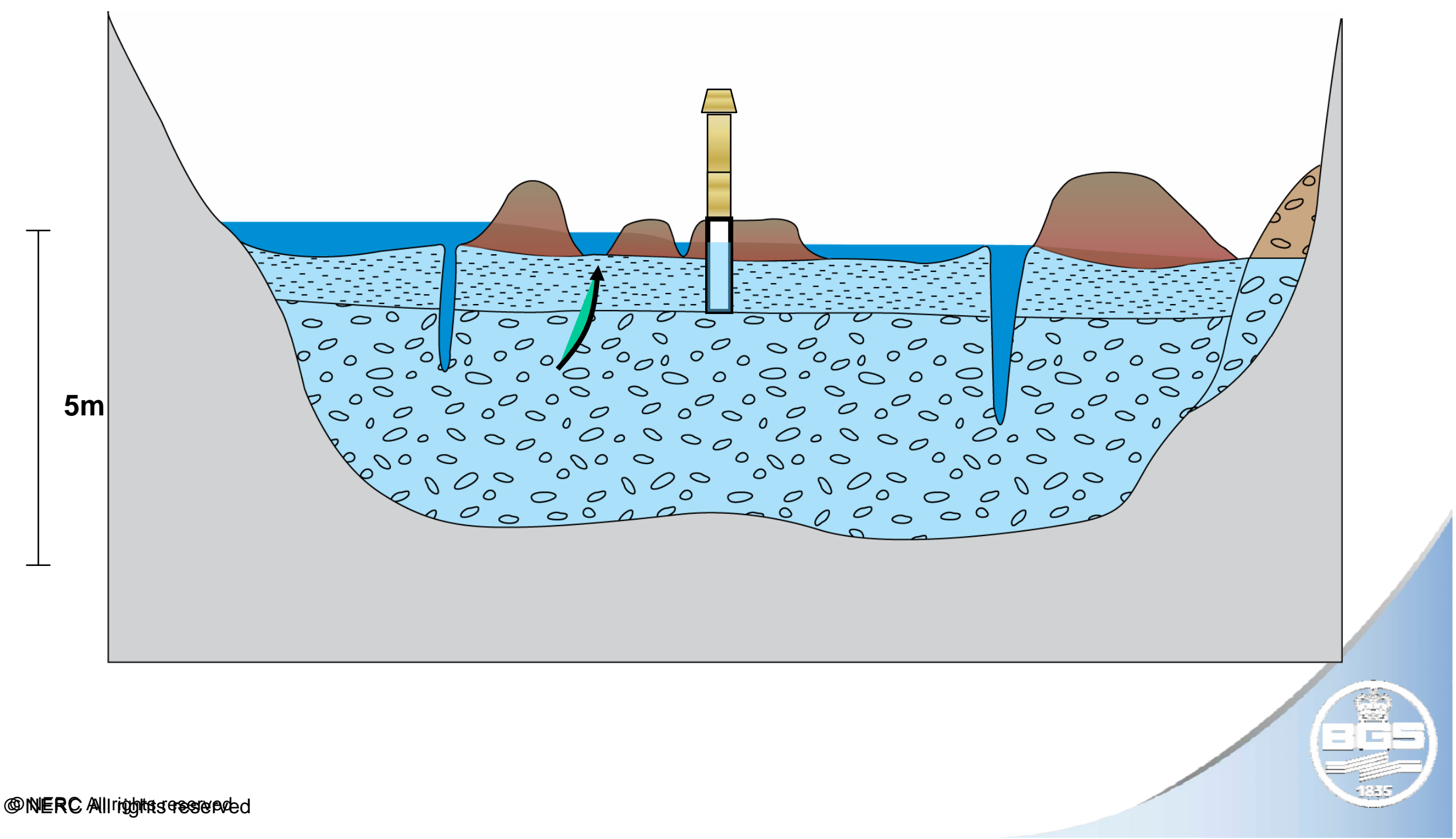




\section{Conceptual model Oxford flooding}

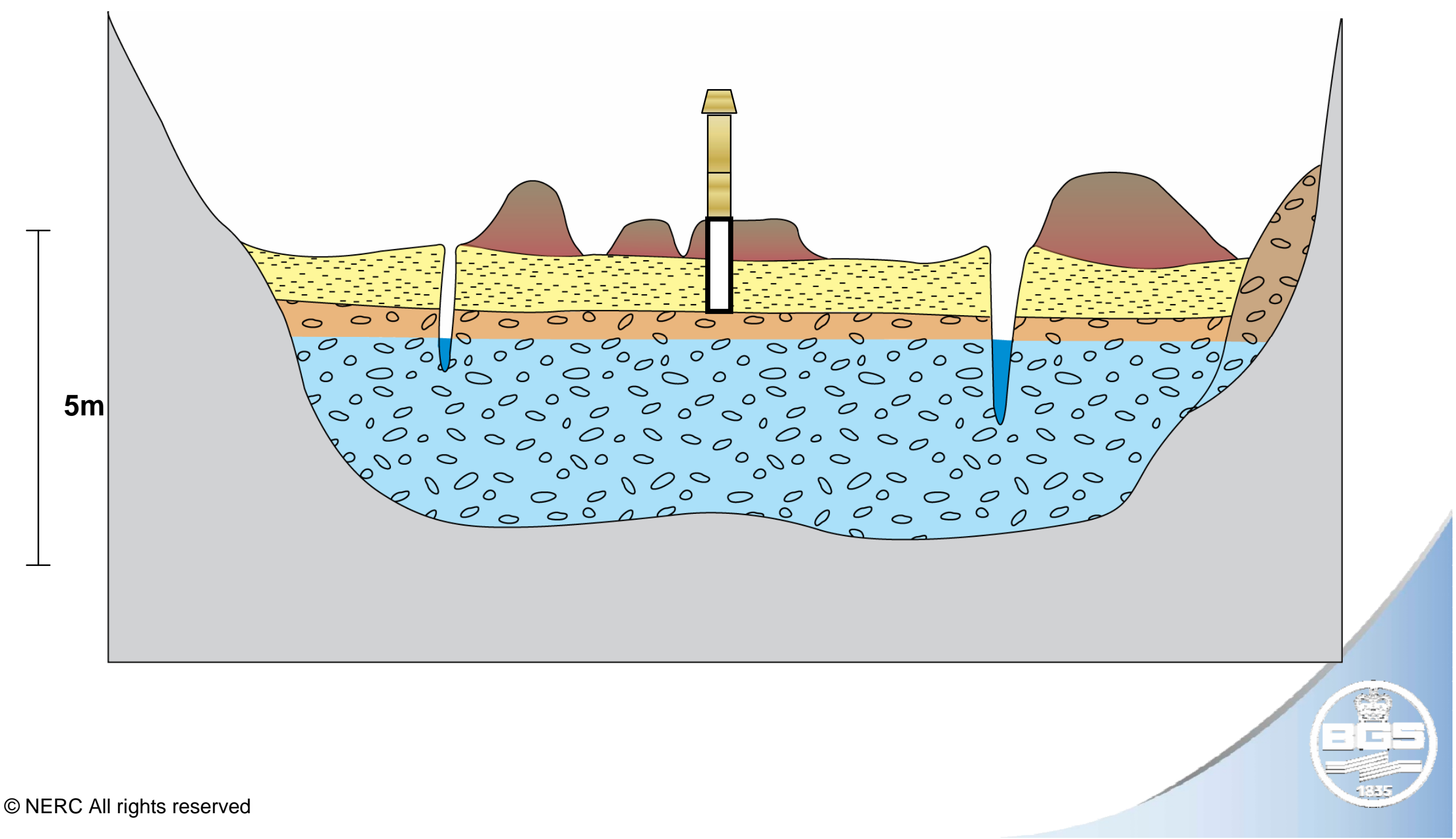




\section{Conceptual model Oxford flooding}

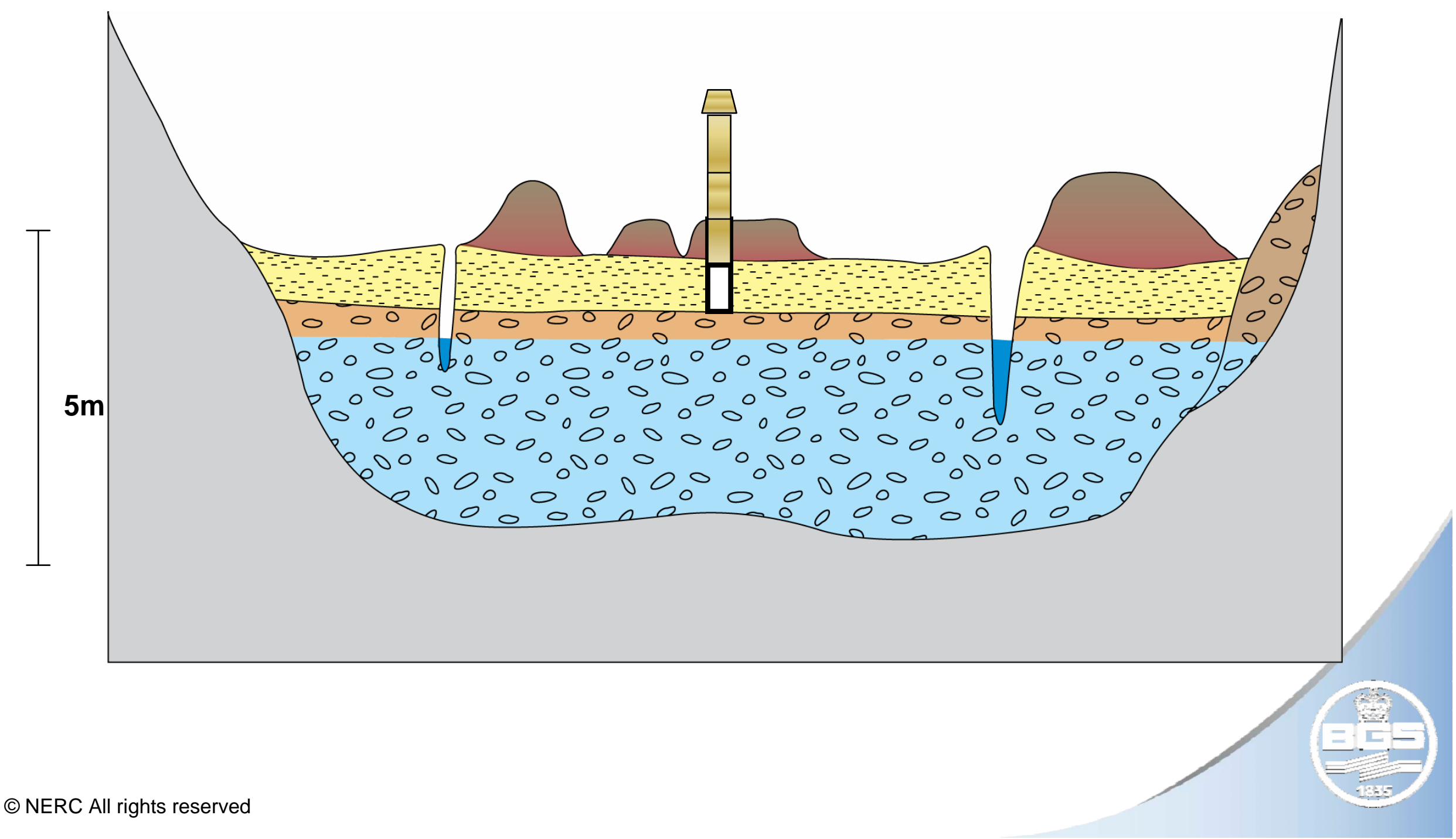




\section{Conceptual model Oxford flooding}

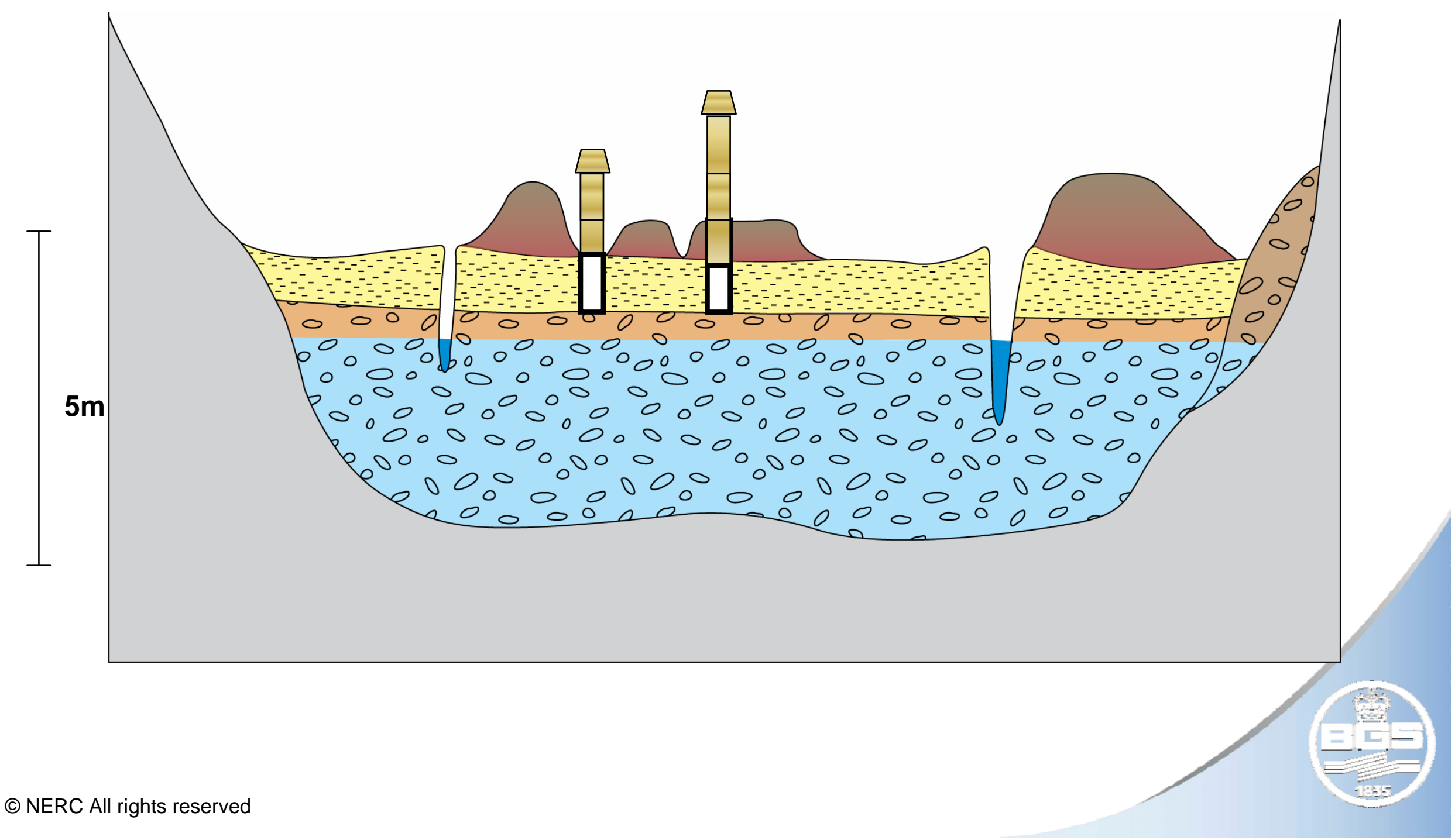




\section{Conceptual model Oxford flooding}

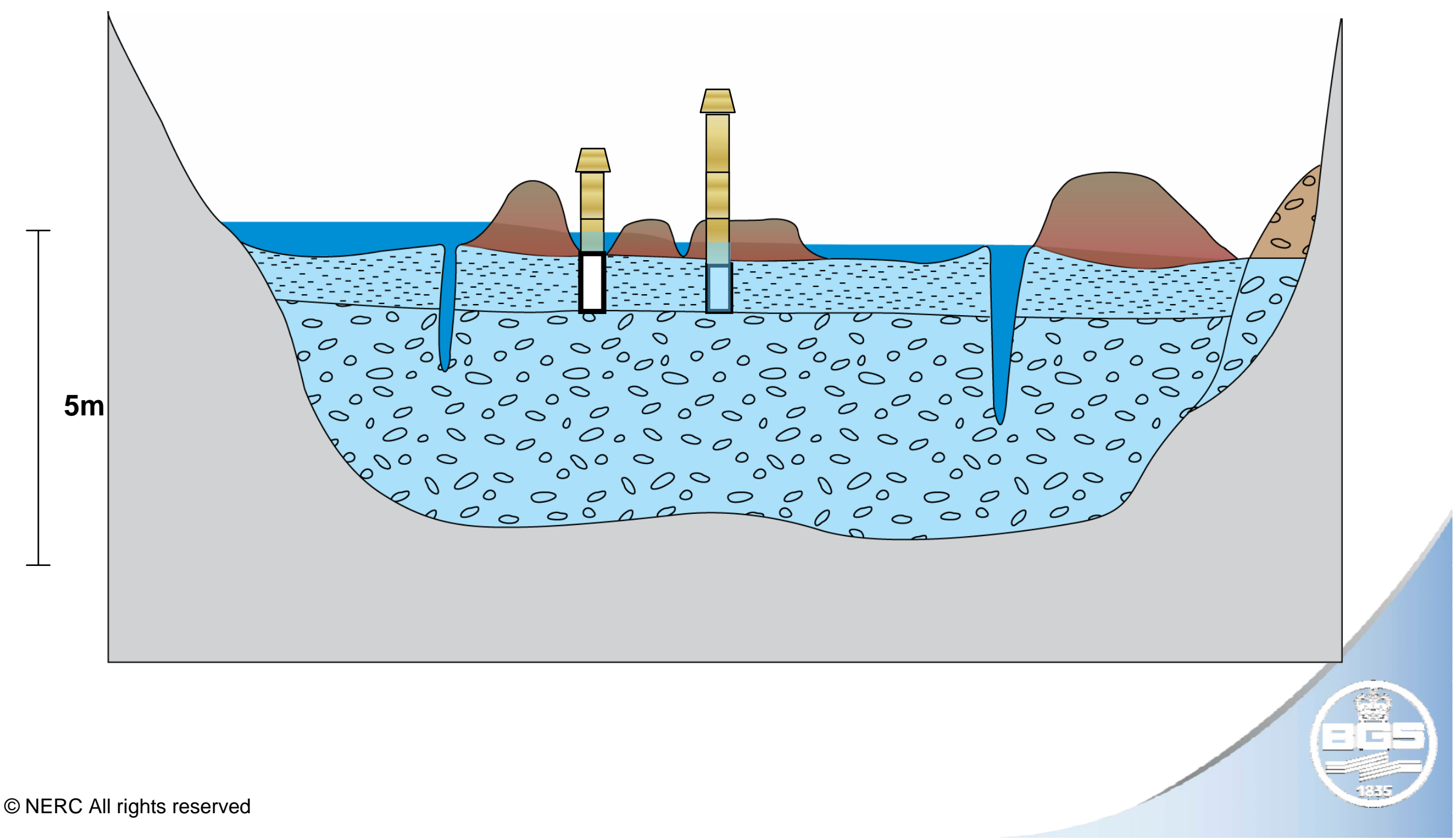




\section{Groundwater flooding of basements}

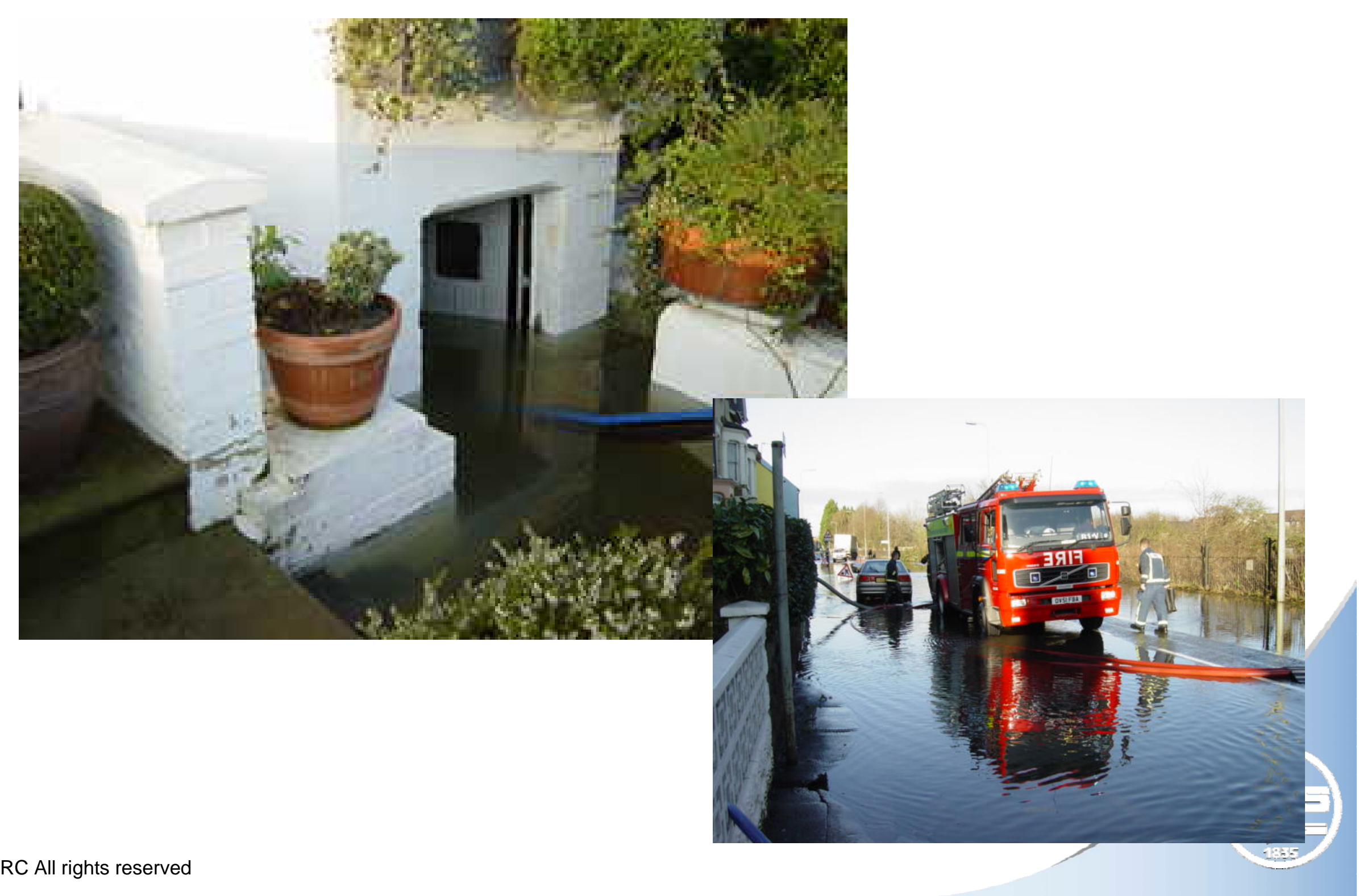




\section{Modelling future groundwater levels}

\begin{tabular}{|l|l|l|l|}
\hline Model & Spatial detail & Parameters & Number sites \\
\hline R-Groundwater & Lumped & $\begin{array}{l}\text { Local calibration through } \\
\text { Monte-Carlo process }\end{array}$ & 24 sites \\
\hline ZOOMQ3D & $\begin{array}{l}\text { Semi } \\
\text { distributed }\end{array}$ & Regional parameters & $\begin{array}{l}\text { 1-Marlborough and Berkshire } \\
\text { Downs and south-west Chilterns }\end{array}$ \\
\hline
\end{tabular}
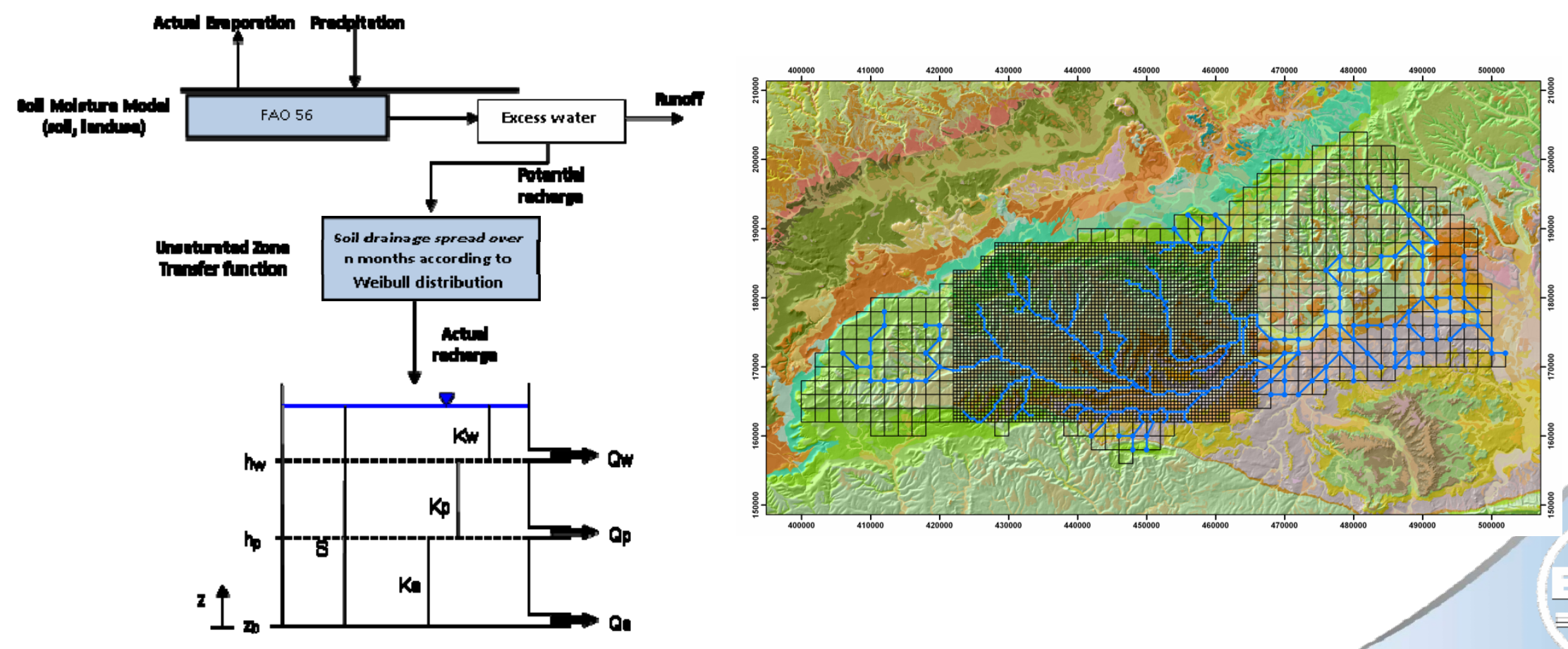


\section{ZOOMQ3D}

- Projections to 2050 under medium greenhouse emissions scenario

- Similarity in projected changes across the selected regional aquifer

- Central estimate of annual change around zero

- Higher late-winter/spring levels? Lower autumn levels?
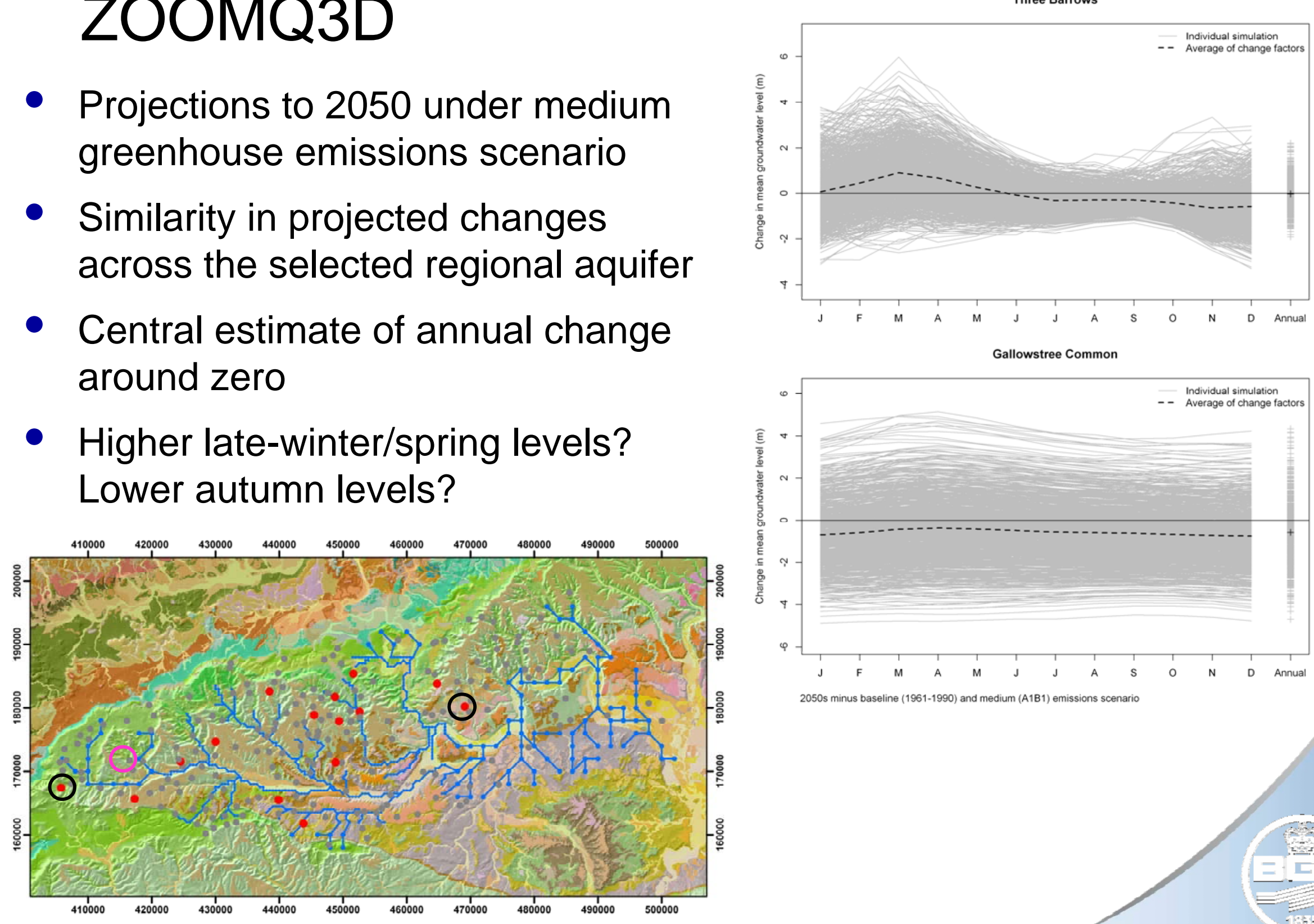

Gallowstree Common

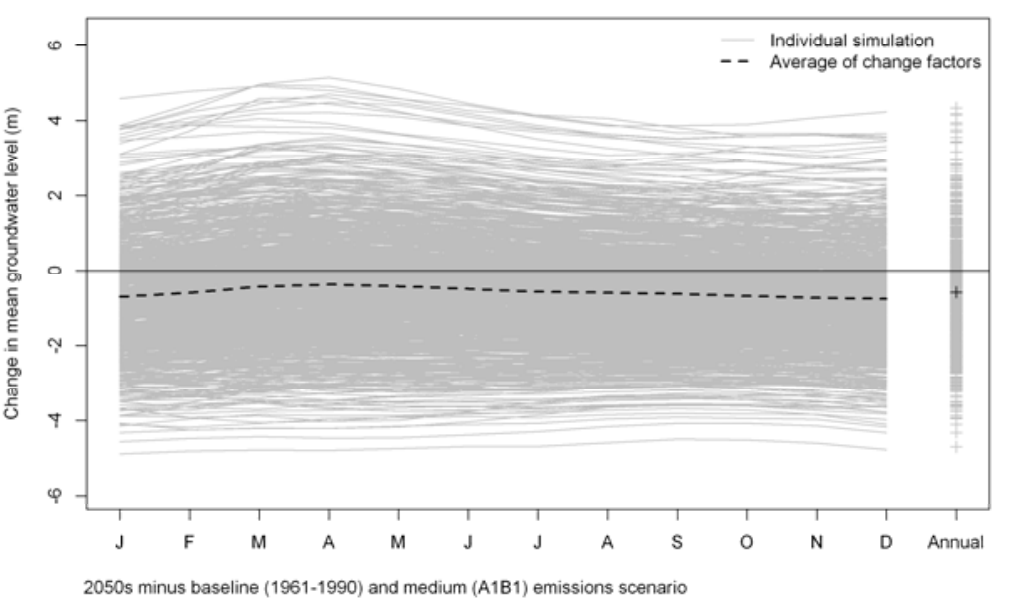




\section{R-Groundwater}

- Mainly National Groundwater Archive 'Index boreholes'

- At least 8-year observed record length

- Support for simplistic approach provided through agreement with detailed regional groundwater model

- Uncertainty is significant.

- Magnitude of change in winter levels greater than changes in summer/autumn levels.

Rockley

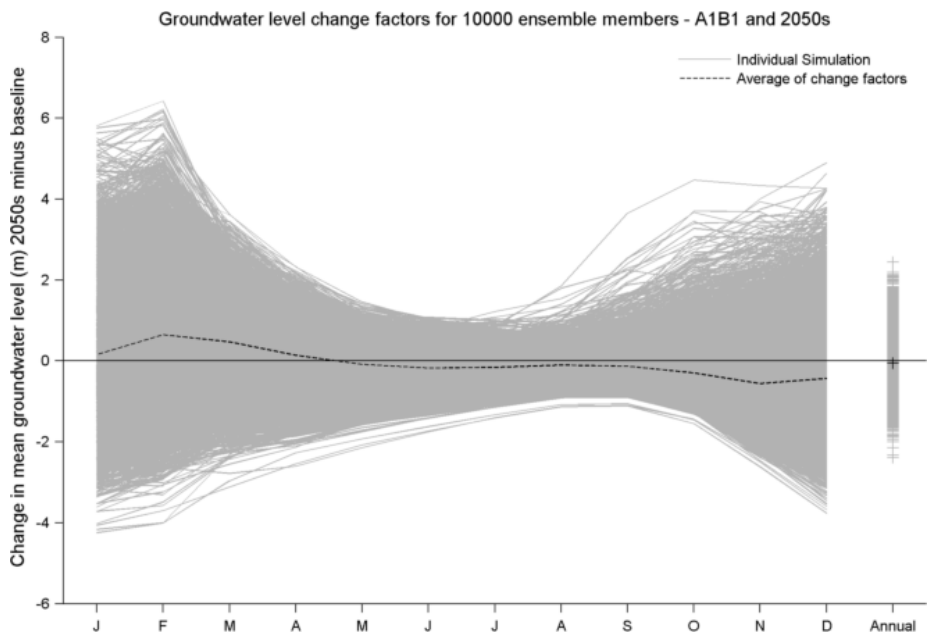




\section{Summary}

- Groundwater bodies in the Thames basin have poor chemical status and increasing trends

- In chalk and limestone upper catchments surface water is predominantly baseflow and influenced by groundwater quality

- Groundwater and surface water interact in the hyporheic zone

- Flood plains are complex areas with shallow groundwater and are subject to inundation which also has quality implications

- In the future, current climate change scenarios lead to changes in the water balance with higher water levels in the winter and drier summers

- Conceptual models are key to understanding the potential impacts of these processes 